\title{
Insect community associated with black cherry (Prunus serotina) in the Allegheny National Forest
}

Craig James Larcenaire

West Virginia University, clarcena@mix.wvu.edu

Follow this and additional works at: https://researchrepository.wvu.edu/etd

Part of the Entomology Commons, and the Forest Management Commons

\section{Recommended Citation}

Larcenaire, Craig James, "Insect community associated with black cherry (Prunus serotina) in the Allegheny National Forest" (2021). Graduate Theses, Dissertations, and Problem Reports. 10326. https://researchrepository.wvu.edu/etd/10326

This Thesis is protected by copyright and/or related rights. It has been brought to you by the The Research Repository @ WVU with permission from the rights-holder(s). You are free to use this Thesis in any way that is permitted by the copyright and related rights legislation that applies to your use. For other uses you must obtain permission from the rights-holder(s) directly, unless additional rights are indicated by a Creative Commons license in the record and/ or on the work itself. This Thesis has been accepted for inclusion in WVU Graduate Theses, Dissertations, and Problem Reports collection by an authorized administrator of The Research Repository @ WVU. For more information, please contact researchrepository@mail.wvu.edu. 
Insect community associated with black cherry (Prunus serotina) in the Allegheny National Forest

\author{
Craig James Larcenaire
}

\author{
Thesis submitted \\ to the Davis College of Agriculture, Natural Resources and Design \\ at West Virginia University \\ in partial fulfillment of requirements for the degree of \\ Master of Science in \\ Plant and Soil Sciences - Entomology
}

Yong-Lak Park, Ph.D., Chair

Michael Gutensohn, Ph.D.

Richard Turcotte, Ph.D.

Division of Plant and Soil Sciences

Morgantown, West Virginia

2021

Keywords: Prunus serotina, black cherry, flower volatiles, pan traps, forest management, dipteran pollinators, Allegheny National Forest

Copyright 2021 Craig James Larcenaire 


\begin{abstract}
Insect community associated with black cherry (Prunus serotina) in the Allegheny National
\end{abstract}

Forest

\title{
Craig Larcenaire
}

Black cherry (Prunus serotina Ehrh.) is valuable species managed for its economic and ecologic benefits. This species grows best in the environment of the Allegheny Plateau region in northwestern Pennsylvania. Land managers on the Allegheny National Forest (ANF) have been managing black cherry for a variety of goals and purposes. Over the last few decades, the land managers have noticed a decline in the natural regeneration of black cherry in the forest. Because the black cherry flowers are self-incompatible and require animal pollinators to transfer the pollen from one tree to another one hypothesis for this decline could be a deficiency of insect pollinators. There are little published studies documenting pollinators in the forest canopy ecosystem. Even less literature is available regarding the pollinators of black cherry flowers. My research presented in this thesis is intended to answer these questions about the insect pollinators of black cherry.

First, we conducted a survey in the canopies of black cherry in two mixed upland hardwood stands in the ANF. We surveyed for seven days before, during and after peak flowering of black cherry using color pan traps. We found that Diptera was significantly more abundant $(\mathrm{P}<0.05)$ in the canopies during peak flowering. Based on the insects directly sampled from the flowers we confirmed that insects in the orders Hymenoptera, Diptera, and Coleoptera carried black cherry pollen on their bodies. In addition, the volatile organic compounds (VOCs) of the flowers were analyzed using a closed-loop stripping method combined with GC/MS. We found two chemotypes emitted by the flowers with a mix of approximately thirty different compounds. The blend emitted consisted of several monoterpenes with the isomers (E)- and (Z)$\beta$-ocimene as the dominant compound detected.

Next, we surveyed insects during the peak flowering of black cherry in three different harvesting treatment types in the ANF. These stands were defined by the foresters in the ANF as shelterwood seed tree, shelterwood removal stand treatments, and unmanaged. The shelterwood seed tree treatment is the first stage of a harvest cycle which involves removing approximately one-third of the overstory canopy trees, leaving mature black cherry to seed in the next generation. The shelterwood removal cut is the final stage of harvest and removes all the merchantable tree species in the stand. The overstory is almost completely removed, favoring the understory vegetation. The mixed-age upland hardwood stands have no recent history of management and were used as the control stand.

We found the order Diptera to be most abundant in all stand types, with the highest trap captures in the shelterwood seed tree treatment. The lowest species diversity and richness was found in the canopy of the removal stand. The top ten most prevalent insects composed $\sim 69 \%$ of the total trap captures and many of these species showed a preference toward the canopy in each of the stand types. 
The results of my studies elucidate which insects are associated with the canopies of black cherry in the ANF. These data can be used to answer questions about black cherry regeneration decline and aid in future management decisions. 


\section{Acknowledgment}

I would like to thank my advisor, Dr. Yong-Lak Park, for his guidance and encouragement during this project. I am very grateful and appreciative to my committee members Dr. Richard Turcotte and Dr. Michael Gutensohn for their motivation, patience, and guidance throughout my degree. I feel lucky to have had such a cohesive committee that made working on this project very pleasant. I am very grateful to Fumin Wang for all the helpful conversations and instruction you provided on many aspects of this project. Thank you very much to Ida Holaskova for your countless hours putting together the complex statistical analysis for this project. I also thank Robert Acciavatti, Andrea Kautz, Sam Droege, and Vicki Kondo for their taxonomic expertise and help with insect identifications. Thank you to my colleagues William Oldland, Danielle Kelley, Heather Smith and Tim Tomon for their input and assistance in the field during this project and to Kristen Wickert and Emmalyn Sheridan for helping to sort insects in the lab. Thank you to the Forest Service staff in the Allegheny National Forest for their help with study locations. I am also very grateful to my lab-mates Braley Burke and Jaewon Kim for their peer support during our time together at WVU.

I would especially like to thank my wife Dana for taking such great care of our two incredible boys Landen and Luke while I traveled and worked long nights. Their encouragement gave me the motivation to keep moving forward and finish my degree. I am very fortunate to have such a loving and supporting family. 


\section{TABLE OF CONTENTS}

Insect community associated with black cherry (Prunus serotina) in the Allegheny National Forest

ABSTRACT

TABLE OF CONTENTS

ii

LIST OF TABLES

vii

TABLE OF FIGURES viii

CHAPTER 1: INTRODUCTION

Thesis organization

General Introduction

Objectives of Study

Literature Review

Allegheny National Forest

Range and life history of black cherry

Economic values of black cherry

Silvicultural management

Sampling with pan traps

Pollination

Volatile organic compounds in flowers 9

Literature Cited

Chapter 2: Characterization of the Insect Assemblage and Associated Floral Volatiles of Black Cherry (Prunus serotina)

Abstract:

1. Introduction

2. Results 20

3. Discussion

4. Materials and Methods

Supplementary Materials:

References

Chapter 3: Effects of forest stand type on the insect assemblages of black cherry (Prunus serotina) in the Allegheny National Forest 
Abstract

Materials and Methods

Results

Discussion 65

References Cited

69

Chapter 4. Conclusion 


\section{LIST OF TABLES}

Chapter 2 Characterization of the Insect Assemblage and Associated Floral Volatiles of Black Cherry (Prunus serotina)

Table 1. Major insect species captured per day $( \pm \mathrm{SE})$ in the canopy and ground traps during the flowering period $\left(\alpha=0.05 ;^{*}, \mathrm{p}<0.05 ; * *, \mathrm{p}<0.01\right)$.

Table 2. Volatile organic compounds identified in the headspace of Prunus serotina flowers

Chapter 3 Comparing insect abundance and diversity of three forest stand types in the Allegheny National Forest

Table 1. Totals and percentages of insect orders captured in each stand type

Table 2. Simpsons Index of Diversity (D) and species richness was calculated for each order individually to see where the most diversity and richness occurred. These data show the high richness and diversity was found in the ground traps for most orders.

Table 3. The top ten most abundant insect species captured in this study.

Table 4. The most prevalent insect species are found in all the stand types in high

abundance.

Table 5. The vegetation survey revealed more understory herbaceous species in the control with 39 different plant species. The shelterwood had the second most with 22 and the removal had the least with 18 . A higher understory vegetation abundance helps explain why insect species and diversity were highest in the ground traps. 


\section{TABLE OF FIGURES}

Chapter 2 Characterization of the Insect Assemblage and Associated Floral Volatiles of Black Cherry (Prunus serotina)

Fig. 1. Mosaic chart showing the proportion of insect orders captured in the ground and canopy traps. The total trap captures across all trapping periods on the ground were 3,878 (563 per day) and 5,655 (822 per day) in the canopy.

Fig. 2. . Captures of insects by orders in two trap locations (ground and canopy) and three trapping periods (before, during, and after flowering). Main effect of trap position (a) in doubly repeated measures ANOVA is indicated $(\alpha=0.05 ; *, p$ $<0.05 ; * *, p<0.01 ; * * *, p<0.001)$ and different letters in each insect order (b) indicate a significant difference in trap captures among flowering periods based on Tukey-Kramer test at $\alpha=0.05$.

Fig. 3. A total of 9,533 insects captured in the traps, and Diptera was the most abundant (64.1\%). Significantly more insects in Diptera, Lepidoptera, and Thysanoptera were captured the traps installed in the canopy than those on the ground, and Anthalia bulbosa (Diptera: Hybotidae) was the dominant species visiting the canopy of black cherry.

Fig. 4. Flowers and pollen grains of black cherry: (a) black cherry raceme in full bloom; (b) a black cherry flower with 5 white petals and 14-15 stamens surrounding a single pistil; (c) anthers after dehiscence; (d) SEM image of pollen grains on anther; (e) SEM image of black cherry pollen grains found on the thorax of Tipula sp. (Diptera: Tipulidae); (f) black cherry pollen grains captured in insect hairs showing the unique exine sculpturing.

Fig. 5. Black cherry pollen grains found on insect body: (a) Antocha sp. (Diptera: Limoniidae); (b) Atalantycha bilineata (Coleoptera: Cantharidae); (c) Camponotus pennsylvanicus (Hymenoptera: Formicidae); (d) Trichopion sp. (Coleoptera: Curculionidae); and (e) Drosophilinae (Diptera: Drosophilidae). 52

Fig. 6. Heatmap and hierarchical clusters (groups 1-3) based on profiles of major floral volatile compounds in Prunus serotina and other Prunus species. Relative abundances (\%) of volatile compounds were normalized by a shifted-log transformation. Prunus species and cultivars were hierarchically clustered by Ward's minimum variance method on Euclidean distances. Classes of floral volatile compounds: TER, terpenes and derivatives; PHE, phenylpropanoids/benzenoids; FAD, fatty acid derivatives; AHC, alkane, and alkene hydrocarbons. * data reported in this study. 
Chapter 3 Effects of forest stand type on the insect assemblages of black cherry (Prunus serotina) in the Allegheny National Forest

Fig. 1. Satellite image of the three stand types in Bradford. Three mature black cherry trees were chosen at random within these boundaries using random points in Arc GIS and a random number generator. The differences in canopy cover between the three stands is easily seen in this image.

Fig. 2. A.) Pan trap ground array, $12 \mathrm{oz}$ plastic cups with blue and yellow fluorescent paint. This trap was positioned $\sim 12$ inches off the ground. B.) Canopy trap array hung in black cherry circled in red. These traps were hung half-way into the canopy of the tree $\sim 60-80$ feet from the ground.

Fig 3. Comparison of insect orders in each stand type. The orders that showed significance at $\alpha=0.05$ were given letters above the bars. Significance was tested within the order and was not tested comparing all interactions.

Fig 4. The ground and canopy traps were compared with all the sites combined. The asterisk above the bars indicates significant difference in trap position for the insect order at $\alpha=0.05$.

Fig 5. A significant interaction for the stand type and trap position was detected for the order Lepidoptera. This graph indicates that lepidopterans are more abundant in the canopies of black cherry in the shelterwood and control stands. The different letters above the bars indicate significance at $\alpha=0.05$. 


\section{CHAPTER 1: INTRODUCTION}

\section{Thesis organization}

This thesis is organized into four chapters. Chapter 1 provided a general introduction to the study and a literature review. Chapter 2 determined the insects that visit the canopies of black cherry in the forest and the volatile organic compounds emitted by black cherry flowers. Chapter 3 investigated the abundance and species diversity of insects in three different stand types of black cherry in the Allegheny National Forest. Chapter 4 provides a general conclusion for this study. Chapter 2 of this thesis was prepared according to the publication guidelines established by the journal Plants and the other chapters were prepared according to the guidelines established by the Entomological Society of America.

\section{General Introduction}

The Allegheny National Forest (ANF) was established in 1923 and is Pennsylvania’s only National Forest. This area of the northeast is world-renowned for its production of highquality black cherry (Prunus serotina) timber. Since the early 2000s the land managers have noticed the natural regeneration rates of the black cherry have been declining. This decline could be caused by many different factors such as deer browse, soil pathogens, clean air act, lack of insect pollinators. Because of the lack of knowledge involving pollinators on black cherry, my research focused on insect pollination, one of the potential causes of the black cherry decline. The strategies implemented through silviculture are helpful in managing forest stands to produce high-quality trees for the timber market. However, the activities involved in harvesting can 
disturb the soil surface. This suggests that understanding which insects are responsible for pollination and which type of habitat these insects require could affect the prescribed treatment.

The outputs and outcomes of this study would add knowledge of which insects are associated with black cherry flowers and how management affects the abundance and diversity of insect communities. This study also provides the first documentation of the volatile organic compounds emitted by the flowers of black cherry. These data are important to help answer the question of why the black cherry regeneration decline is occurring on the ANF.

\section{Objectives of Study}

The objectives of this study were to better understand which insects are potentially pollinating the flowers of black cherry and which volatile organic compounds the flowers emit to attract insect pollinators.

1. Describing the insect communities in the forest using canopy pan traps and the flower volatile organic compounds of black cherry (Prunus serotina) trees (Chapter 2).

2. Comparing the insect communities in the canopies of black cherries in three different stand treatment conditions. (Chapter 3). 


\section{Literature Review}

\section{Allegheny National Forest}

The Allegheny National Forest (ANF) is in northwestern Pennsylvania and covers approximately 513,175 acres. The forest ranges from approximately 1,000 to 2,300 feet in elevation (Huebner et al. 2009). This topography is typical in the northwest corner of Pennsylvania on the Allegheny Plateau is where the best development of black cherry occurs (Marquis 1990). The Forest is spread across Elk, McKean, Forest, and Warren counties and split into two ranger districts (i.e., Marienville and Bradford). The ANF is managed for a variety of land uses, including recreation, wildlife habitat development, forest products, and oil and gas development (USDA Forest Service 2007).

The original tree composition of the ANF included American beech (Fagus grandifolia), eastern hemlock (Tsuga canadensis), with smaller components of sugar maple (Acer saccharum), birch (Betula spp.), white pine (Pinus strobus) and chestnut (Castenea dentata) (Morin et al. 2006, Black et al. 2006). In the early $19^{\text {th }}$ century, the land was cleared for agriculture and to provide timber for cabins. During the 1850 s the leather industry began to use hemlock bark as a source of tanning to cure leather (Morin et al. 2006). The civil war created a high demand for leather for use in harnesses, military equipment, and industrial belting. The increased demand led to the increase of tanneries and the extensive harvesting of hemlock (Morin et al. 2006).

Today, the desired mix of forest types in the ANF is $33-47 \%$ upland hardwoods, $21-28 \%$ Allegheny hardwoods, 15-17 percent oak, 12-16\% northern hardwoods, 1-2\% hemlock 1-3\% conifer, and $1 \%$ aspen. The Allegheny hardwood type is an intermediate forest type defined as a 
stand with at least $50 \%$ of the basal area consisting of black cherry, yellow poplar, and/or white ash. Black cherry is usually dominant in these stands in the ANF (USDA Forest Service 2007).

\section{Range and life history of black cherry}

Prunus serotina, is commonly known as black cherry, rum cherry, mountain cherry, and is a member of the Rosaceae family. Rosaceae is a large family consisting of approximately 122 genera of trees, shrubs and herbs with 3,370 species worldwide (DeVore and Pigg 2007). Black cherry is the largest of the native cherries and is the only species in the genus Prunus with commercial timber value (Hough 1960). A mature tree can grow to heights of 80 to 100 feet and has an average lifespan of around 100 years (Marquis 1990). The bark of mature black cherry trees is distinguishable by their dark flakey reddish-brown upturned plates. The leaves are simple, alternating, and lanceolate with a finely serrated margin. The flowers have five small white petals, have both male (anthers) and female (stigma) reproductive organs which are situated on a $10-15 \mathrm{~cm}$ long inflorescence called a raceme. These flowers are self-incompatible, which means pollen from the anthers of another black cherry tree is required for successful germination of the ovule (Forbes 1969). Unlike other domestic cherries that flower before the leaves appear, the flowers of black cherry do not appear until after the leaves are out. On the Allegheny Plateau the flowers begin to bloom around mid-May. Flowers typically come into bloom through a gradient from base to apex. The successfully cross-pollinated flowers produce a dark red or black drupe which contains a single seed. The pulp of the fruit is thin, bitter-tasting and typically begins to ripen from mid-August to early September.

Black cherry grows best on podzol and gray-brown podzolic soils within its native range (Hough 1965). The true podzol soils originating from the Dekalb-Leetonia group and associated 
soil types such as Cookport and Clymer silt loams provide the best development conditions in the Allegheny Plateau (Hough 1960).

\section{Economic values of black cherry}

When grown in the ideal conditions black cherry can be very valuable and is the only member of the genus Prunus to be valued for its quality timber (Hough 1960). The wood is valued by craftsmen for its deep color, quality, and easy workability to produce cabinets and furniture. According to Jacobson (2018), the market value of black cherry timber in 2018 was an average of $\$ 792$ per 1000 board feet (MBF). Red oak fetches the next highest price at $\$ 492$ per MBF. In 2019 the price of timber fell to $\$ 604$ per MBF for black cherry but was still more valuable than northern red oak at $\$ 382$ per $\mathrm{MBF}$.

Black cherry was introduced to Europe in the $17^{\text {th }}$ century and planted extensively in the early $18^{\text {th }}$ century with the intent to produce high-quality timber (Muys et al. 1992). The dream of high-quality timber production never materialized so the plantings shifted to soil amelioration, to serve as wind and firebreaks and to improve litter quality in coniferous forests (Pairon et al 2006). These introductions have caused the European economy ca. 25 million euros annually to control (Schilthuizen et al. 2016).

Black cherry has an important ecological value in its native range as well as economy. The fruit is consumed by bears, dear, foxes, squirrels, turkeys, and roughed grouse (Beeman and Pelton 1980, Nelson and Martin 1953, Hough 1960). The fruit has also been used by humans for producing jams, jellies, fermented beverages and is regarded to be medicinal by Native Americans (Speck 1917, Rios-Corripio and Guerrero-Betrán 2020). The flowers of the tree can also be an important source of pollen and nectar for anthophilous insects. 


\section{Silvicultural management}

The high value of black cherry means that it is managed by landowners to be sold on the timber market. Managing the forests in the United States is said to have begun in 1864 when President Abraham Lincoln set aside the Mariposa Sequoia Forest in Northern California (Manheim 2010). The Forest Service was officially established as a forest conservation agency in 1905 by President Theodore Roosevelt (Manheim 2010). Since that time the forest service has been managing the nation's forests and grasslands for multiple uses, including the sustained yield of renewable resources such as clean water, wildlife, forage, recreation, and wood (USDA Forest Service 2021). Even age stand management is a method that uses a planned sequence of treatments that will maintain and regenerate a stand with predominately one age class. An even age stand is defined as a stand of trees with a range of tree ages less than 20 percent of rotation (Bettinger et al. 2017). The ANF uses the shelterwood seed cut and shelterwood removal cut with reserves as the management tool of black cherry in the forest (USDA Forest Service 2007).

These treatments will change the structure of the stand and the surrounding forest. The vegetation species will be reduced by completing these treatments. This removes and alters habitats for animal species like insects. Additionally, the use of heavy machinery in the stand can compact soil where many insect species overwinter and pupate (Hutchings et al. 2002). Studies have suggested that some insects like lepidopterans are particularly susceptible to these changes and insects like solitary bees will tend to thrive (Hanula et al. 2015, Jackson et al. 2014). 


\section{Sampling with pan traps}

To sample anthophilous and pollinator insects several different methods can be used. Some of these include malaise traps, flower observations, sweep netting, vacuuming sampling, vane traps, and pan traps (O’Connor et al. 2019). Each one of these methods has inherent advantages and disadvantages. Malaise traps are large tent-like apparatus with open sides that intercept insects in flight. The insects then crawl up the sides of the tent into a collection apparatus (Matthews and Matthews 2017). These traps are large, cumbersome, and conspicuous in the forest which can lead to damage from curious wildlife. These traps can also be biased toward certain insects depending on mesh size and orientation of the trap with the wind (Pruess and Pruess 1966, Darling and Packer 1988). Flower observations use standardized timed intervals to observe flowers and count and identify visiting insects (Roy et al. 2016). This method gives a direct correlation between the insects identified and the subject flower. However, it is time-consuming, relies on expert knowledge of a wide variety of insects for reliable identifications and may be biased toward larger insects. Sweep netting uses fine mesh or canvas bags attached to a pole to collect insects by sweeping the net across vegetation. The insects are collected in the net and can be stored for identification or identified and released (Doxon et al. 2011). This method can provide a larger sample of insects and identifications of the insects can be completed later by specialists. There is not a direct connection of flower visitation by the insects with this method. Vacuum sampling is like sweep netting, but instead of a net, a modified vacuum is used to collect insects that visit the flowers. This will provide a direct connection with the flower and insect but may be more biased toward smaller invertebrates (Doxon et al. 2010). Vane traps usually consist of a plastic collection jar, and two interconnecting semi-transparent 
vanes, usually colored blue or yellow (Hall and Reboud 2019). This style of trap is typically low cost, easy to deploy and low maintenance, however, does not show a direct connection to the insects and flowers. Pan traps are similar to vane traps except for these use cups with ultraviolet pigmented paint to color the inside blue, or yellow. Pan traps are colored plastic cups filled with soapy water to break the surface tension of the water and trap insects that land inside (Tuell and Isaacs 2009). Colors like blue, white and yellow been have each been demonstrated to attract certain insect orders better than others (Shrestha et al. 2019, Wilson et al. 2016).

\section{Pollination}

Plants must use a variety of different strategies to spread their genes through sexual reproduction. There is abiotic pollination through the wind (anemophily) and water (hydrophily) and biotic pollination through animals such as insects (entomophily) (Midgley and Bond 1991, Philbrick 1991). Many angiosperm species bear perfect flowers like black cherry; however, a significant portion of angiosperms are able to self-pollinate (Schoen et al. 1996). This strategy (autogamy) is believed to be a product of evolution that gives selective advantage to assure seed production when pollinators are insufficient. However, self-incompatibility is an important mechanism used by flowering plants to prevent self-fertilization and thereby generate and maintain genetic diversity (Takayama and Isogai 2005). This process of cross-pollination and cross fertilization is known as allogamy.

The main systems of self-incompatibility are homomorphic (i.e., many different incompatibility types) or heteromorphic (i.e., only two or three different incompatibility types) (Charlesworth 2010). The most common form of self-incompatibility is gametophytic selfincompatibility, which refers to the fact that the pollen is determined by its own (haploid) $S$ 
genotype. The sporophytic self-incompatibility type refers to the fact that the behavior of the pollen is determined by the diploid $S$ geneotype of the pollen producing plant. Prunus species typically exhibit the gametophytic self-incompatibility system (Newbigin et al. 1993). The reaction inhibiting self-pollination is triggered when the same $S$-allele specificity is expressed in both the pollen and pistil (Tao and Lee 2010). This phenomenon is controlled by a single locus, the $S$ locus, with many alleles, several hundred in some cases (Newbigin et al. 1993). Recent research has identified the genes controlling the self-incompatibility recognition in Prunus. The F-box genes at the $S$ locus control the male (pollen), and the ribonuclease genes control the female (pistil) specificities. These plants will use a self/non-self-recognition process in the pistil that will inhibit self-pollen tube development. Because fruit set is unable to occur without successful cross pollination, it is essential that cross compatible cultivars are inter-planted.

\section{Volatile organic compounds in flowers}

The size, shape, structure, and color of flowers are traits that will affect the activeness of pollinators and therefore, plant reproductive success (Asikainen and Mutikainen 2005).

However, the influence of floral scent in the attraction of pollinators has been suggested as as the main driver for visitation by pollinators (Klatt et al. 2013). Floral volatiles compounds (VOCs) are lipophilic compounds with low molecular weight and high vapor pressure at ambient temperature (Dudareva et al. 2013). These compounds are responsible for floral scents, and other essential plant functions (Tholl 2006).

Terpenoids are the largest class of small molecule natural products produced by plants (Buchanan 2015). Each compound has a unique chemical structure but shares the same biosynthetic origin. Terpenoids were once believed to be metabolic waste products but have 
since been found to contribute to a variety of functions like plant defense and pollinator attraction. The two pathways responsible for the biosynthesis of terpenes are the methylerythritol 4-phosphate (MEP) and mevalonate pathways (Buchanan 2015).

Phenylpropanoids and benzenoids are the second largest family of aromatic compounds which are derived from the aromatic amino acid phenylalanine (Seigler 1998). Phenylalanine is first synthesized through the shikimate/phenylalanine pathways (Buchanan 2015). The first step of the biosynthesis of benzenoid and phenylpropanoid compounds is catalyzed by the Lphenylalanine ammonia-lyase (PAL) enzyme (Muhlemann et al. 2014). Benzoates are derived through the cinnamyl-CoA esters in the monolignol pathway. Phenylpropanoids are derived through the monolignol pathways via the BAHD acyltransferase (Buchanan 2015). The five groups of phenylpropanoids are flavonoids, monolignols, phenolic acids, stilbene and coumarins (Deng and Shanfa Lu 2017). These compounds are primarily used for plant defense, UV protection, pigmentation, structural support, and pollinator attraction (Fraser and Chapple 2011, Ferrer et al. 2008).

Fatty acid derivatives are another class of floral VOCs and are derived from unsaturated $\mathrm{C}_{18}$ fatty acids, linolenic and linolenic (Mulemann et al 2014). The biosynthesis of these VOCs is initiated by oxygenation of the octadecanoid precursors, catalyzed by a lipoxygenase (LOX) which leads to a formation of 9- and 13-hydroperoxy intermediates. These can then enter two different pathways to create volatile compounds. The products can be used to signal plant defense response by signaling herbivore predators, antimicrobial agents and as attracts of pollinators.

Because of their importance as an agricultural crop, the attractiveness of the floral volatiles in the genus Prunus has been documented. The literature reveals that the primary 
components are diverse in each cultivar and species. The common chemical shared between species is Benzaldehyde, while other minor compounds include Benzyl alcohol, Benzyl acetate, Hexanol, Phenylethanol, and Cis-3-Hexane-1-ol (Hao et al. 2014, El-Sayed et al. 2018, Zhang et al. 2020). These chemotypes among groups occur because VOC synthesis is regulated by the expression of related genes and enzyme activity (Zhang et al. 2020).

\section{Literature Cited}

Asikainen, E., and P. Mutikainen. 2005. Pollen and resource limitation in a gynodioecious species. American Journal of Botany 92: 487-494.

Beeman, L. E., and M. R. Pelton. 1980. Seasonal foods and feeding ecology of black bears in the Smoky Mountains. Bears: Their Biology and Management 4: 141-147.

Bettinger, P., K. Boston, J. P. Siry, and D. L. Grebner. 2017. Chapter 4 - Estimation and Projection of Stand and Forest Conditions, 87-111. In Forest Management and Planning (2nd Edition), Academic Press. San Diego, C.A.

Black, B. A., C. M. Ruffner, and M. D. Abrams. 2006. Native American influences on the forest composition of the Allegheny Plateau, northwest Pennsylvania. Canadian Journal of Forest Research 36: 1266-1275.

Block, A. K., M. M. Vaughan, E. A. Schmelz, and S. A. Christensen. 2019. Biosynthesis and function of terpenoid defense compounds in maize (Zea mays). Planta 249: 21-30.

Buchanan, B. B., W. Gruissem, and R. L. Jones. 2015. Biochemistry and molecular biology of plants. John wiley \& sons. Chichester, West Sussex, UK. 
Charlesworth, D., X. Vekemans, V. Castric, and S. Glémin. 2005. Plant self-incompatibility systems: a molecular evolutionary perspective. New Phytologist 168: 61-69.

Darling, D. C., and L. Packer. 1988. Effectiveness of Malaise traps in collecting Hymenoptera: the influence of trap design, mesh size, and location. The Canadian Entomologist 120: 787-796.

Deng, Y., and Lu, S. 2017. Biosynthesis and regulation of phenylpropanoids in plants. Critical Reviews in Plant Sciences 36: 257-290.

DeVore, M. L., and K. B. Pigg. 2007. A brief review of the fossil history of the family Rosaceae with a focus on the Eocene Okanogan Highlands of eastern Washington State, USA, and British Columbia, Canada. Plant Systematics and Evolution 266: 45-57.

Doxon, E. D., C. A. Davis, and S. D. Fuhlendorf. 2011. Comparison of two methods for sampling invertebrates: vacuum and sweep-net sampling. Journal of Field Ornithology 82: 60-67.

Dudareva, N., A. Klempien, J. K. Muhlemann, and I. Kaplan. 2013. Biosynthesis, function and metabolic engineering of plant volatile organic compounds. New Phytologist, 198: 16-32.

Faegri, K., and L. Van Der Pijl. 2013. Principles of pollination ecology. 3rd edition, Pergamon press, Oxford, England.

Ferrer, J. L., Austin, M. B., Stewart Jr, C., and Noel, J. P. 2008. Structure and function of enzymes involved in the biosynthesis of phenylpropanoids. Plant Physiology and Biochemistry 46: 356-370.

Forbes, D.C. 1969. Self-and Cross-Incompatibility in Black Cherry (Prunus serotina), Ph.D. Thesis, University of Florida, Gainesville, FL, USA. 
Fraser, C. M., and Chapple, C. 2011. The phenylpropanoid pathway in Arabidopsis. American Society of Plant Biologists 9: 1-19

Gross, K., M. Sun, and F. P. Schiestl. 2016. Why do floral perfumes become different? Regionspecific selection on floral scent in a terrestrial orchid. PloS One 11: 1-18.

Hall, M. A., and E. L. Reboud. 2019. High sampling effectiveness for non-bee flower visitors using vane traps in both open and wooded habitats. Austral Entomology 58: 836-847.

Hanula, J. L., S. Horn, and J. J. O’Brien. 2015. Have changing forests conditions contributed to pollinator decline in the southeastern United States? Forest Ecology and Management 348: 142-152.

Hao, R., D. Du, T. Wang, W. Yang, J. Wang, and Q. Zhang. 2014. A comparative analysis of characteristic floral scent compounds in Prunus mume and related species. Bioscience, Biotechnology, and Biochemistry 78: 1640-1647.

Hough, A. F. 1960. Silvical characteristics of black cherry (Prunus serotina). Station Paper NE139. Upper Darby, PA: US Department of Agriculture, Forest Service, Northeastern Forest Experiment Station 1-26.

Hough, A. F. 1965. A twenty-year record of understory vegetational change in a virgin Pennsylvania forest. Ecology 46: 370-373.

Huebner, C. D., R. S. Morin, A. Zurbriggen, R. L. White, A. Moore, and D. Twardus. 2009. Patterns of exotic plant invasions in Pennsylvania's Allegheny National Forest using intensive Forest Inventory and Analysis plots. Forest Ecology and Management 257: 258270. 
Hutchings, T. R., A. J. Moffat, and C. J. French. 2002. Soil compaction under timber harvesting machinery: a preliminary report on the role of brash mats in its prevention. Soil use and Management 18: 34-38.

Jackson, M. M., M.G. Turner, and S. M. Pearson. 2014. Logging legacies affect insect pollinator communities in southern Appalachian forests. Southeastern Naturalist 13: 317-336.

Jacobsen, M. 2018. Timber Market Report: 2018 2nd Quarter (https://extension.psu.edu/timbermarket-report-2017-2nd-quarter). accessed on 8 August 2020.

Klatt, B. K., C. Burmeister, C. Westphal, T. Tscharntke, and M. von Fragstein. 2013. Flower volatiles, crop varieties and bee responses. PLoS One 8: 1-7

Manheim, F. T. 2010. A brief history of United States forest management policy. Forestry. Forest, and Wood Technology of the Ukraine 36: 1-9.

Marquis, D. A. 1990. Prunus serotina Ehrh. black cherry. Silvics of North America 2: 594-604.

Matthews, R. W., and J. R. Matthews. 2017. The Malaise trap: its utility and potential for sampling insect populations. The Great Lakes Entomologist 4: 117-122

Midgley, J. J., and J. W. Bond. 1991. How important is biotic pollination and dispersal to the success of the angiosperms? Philosophical Transactions of the Royal Society of London. Series B: Biological Sciences 333: 209-215.

Morin, R. S., A. M. Liebhold, K. W. Gottschalk, C. W. Woodall, D. B. Twardus, R. L. White, and T. E. Ristau. 2006. Analysis of forest health monitoring surveys on the Allegheny National Forest (1998-2001). Gen. Tech. Rep. NE-339. Newtown Square, PA: US Department of Agriculture, Forest Service, Northeastern Research Station. 102: 1-339.

Muys, B., D. Maddelein, and N. Lust. 1992. Ecology, practice and policy of black cherry (Prunus serotina Ehrh.) management in Belgium. Silva Gandavensis 57: 28-45. 
Muhlemann, J. K., Klempien, A., and Dudareva, N. (2014). Floral volatiles: from biosynthesis to function. Plant, Cell and Environment 37: 1936-1949.

Nelson, A. L., and A. C. Martin. 1953. Gamebird weights. The Journal of Wildlife Management 17: 36-42.

Newbigin, E., M. A. Anderson, and A. E. Clarke. 1993. Gametophytic self-incompatibility systems. The Plant Cell 5: 1315-1324.

O'Connor, R. S., W. E. Kunin, M. P. Garratt, S. G. Potts, H. E. Roy, C. Andrews, and C. Carvell. 2019. Monitoring insect pollinators and flower visitation: The effectiveness and feasibility of different survey methods. Methods in Ecology and Evolution 10: 21292140.

Pairon, M., O. Chabrerie, C. M. Casado, and A. L. Jacquemart, 2006. Sexual regeneration traits linked to black cherry (Prunus serotina Ehrh.) invasiveness. Acta Oecologica 30: 238247.

Philbrick, C. T. 1991. Hydrophily: Phylogenetic and evolutionary considerations. Rhodora 93: $36-50$.

Pruess, K. P., and N. C. Pruess. 1966. Note on a Malaise trap for determining flight direction of insects. Journal of the Kansas Entomological Society 39: 98-102.

Rios-Corripio, G., and J. Guerrero-Beltrán. 2020. Physicochemical, antioxidant and sensory characteristics of black cherry (Prunus serotina subsp. capuli) fermented juice. International Journal of Fruit Science 20: 145-163.

Roy H. E., E. Baxter, A. Saunders, and M. J. O. Pocock. 2016. Focal plant observations as a standardised method for pollinator monitoring: opportunities and limitations for mass participation citizen science. PLoS ONE 11: 1-14. 
Schilthuizen, M., L. P. S. Pimenta, Y. Lammers, P. J. Steenbergen, M. Flohil, N. G. Beveridge, P. T. V. Duijn, M. M. Meulblok, N. Sosef, R. V. Ven, R. Werring, K. K. Beentjes, K. Meijer, R. A. Vos, K. Vrieling, B. Gravendeel, Y. Choi, R. Verpoorte, C. Smit, and L. W. Beukeboom. 2016. Incorporation of an invasive plant into a native insect herbivore food web. PeerJ 4: 1-23

Schoen, D. J., Morgan, M. T., and Bataillon, T. 1996. How does self-pollination evolve? Inferences from floral ecology and molecular genetic variation. Philosophical Transactions of the Royal Society of London. Series B: Biological Sciences 351: 12811290.

Seigler D. S. 1998 Phenylpropanoids. Pp. 106-129. In: Plant secondary metabolism. Springer, Boston, MA.

Shrestha, M., J. E. Garcia, J. H. Chua, S. R. Howard, T. Tscheulin, A. Dorin, and A. G. Dyer. 2019. Fluorescent pan traps affect the capture rate of insect orders in different ways. Insects 10: 1-12.

Speck, F. G. 1917. Medicine practices of the northeastern Algonquians. pp. 303-321. In proceedings of the nineteenth international congress of Americanists. December 1915. Washington D.C., USA.

Takayama, S., and A. Isogai. 2005. Self-incompatibility in plants. Annual Review Plant Biology. 56: 467-489.

Tao, R., and A. F. Iezzoni. 2010. The S-RNase-based gametophytic self-incompatibility system in Prunus exhibits distinct genetic and molecular features. Scientia Horticulturae, 124: 423-433. 
Tholl, D., Boland, W., Hansel, A., Loreto, F., Röse, U.S. and Schnitzler, J.-P. 2006. Practical approaches to plant volatile analysis. The Plant Journal 45: 540-560.

Tuell, J. K., \& Isaacs, R. (2009). Elevated pan traps to monitor bees in flowering crop canopies. Entomologia Experimentalis et Applicata, 131: 93-98.

USDA Forest Service. 2007. Allegheny National Forest record of decision for final environmental impact statement and the land and resource management plan. USDA, Allegheny National Forest.

USDA Forest Service. 2021. Managing the land. (https://www.fs.usda.gov/managing-land), accessed on 10 October 2021.

Wilson, J. S., J. P. Jahner, L. Starley, C. L. Calvin, H. Ikerd, and T. Griswold. 2016. Sampling bee communities using pan traps: alternative methods increase sample size. Journal of Insect Conservation 20: 919-922.

Zhang, T., F. Bao, Y. Yang, L. Hu, A. Ding, A. Ding, J. Wang, T. Cheng, and Q. Zhang. 2020. A comparative analysis of floral scent compounds in intraspecific cultivars of Prunus mume with different corolla colours. Molecules 25: 1-11. 


\title{
CHAPTER 2: CHARACTERIZATION OF THE INSECT ASSEMBLAGE AND ASSOCIATED FLORAL VOLATILES OF BLACK CHERRY (PRUNUS SEROTINA)
}

\begin{abstract}
Black cherry is an ecologically important high-value wood. A decline of its regeneration has been reported in the USA, which could be associated with a lack of pollination. This study was conducted to identify insects visiting black cherry flowers, to determine whether insects captured on the flowers carry black cherry pollen, and to identify the volatile organic compounds (VOCs) emitted by flowers of black cherry. A 2-year insect survey was conducted, before, during and after the black cherry bloom. A total of 9,533 insects were captured in traps and Diptera was the most abundant (64.1\%). Significantly more insects in Diptera, Lepidoptera, and Thysanoptera were captured in the traps installed in the canopy than those on the ground, and Anthalia bulbosa (Diptera: Hybotidae) was the dominant species. Electron microscopy analyses demonstrated that insects captured in the canopy indeed carried black cherry pollen. Black cherry flowers emitted a VOC blend that is composed of 34 compounds and dominated by $\beta$-ocimene and several phenylpropanoids/benzenoids. This floral VOC profile is similar to that of other pollinator-dependent Prunus species. This study reports pollinator insects and associated VOCs for the first time that could play a significant role in the pollination and regeneration of black cherry.
\end{abstract}

Keywords: Allegheny National Forest; black cherry; Diptera; floral volatiles; Lepidoptera; pollination; Prunus; volatile organic compound 


\section{Introduction}

Black cherry, Prunus serotina (Ehrh.), is an important tree species both ecologically and economically. The growth form of the bole and stability and superior working qualities of the wood make black cherry a valuable timber crop [1]. There are five subspecies and two varieties of P. serotina throughout North America with various morphologies [2]. The subspecies serotina var. serotina is the most common and is widely distributed throughout eastern North America [2,3]. A mature tree can grow to $20-30 \mathrm{~m}$ and has an average lifespan of 80-100 years [3]. Black cherry can be found growing in woodlands, thickets, roadsides, and fence rows from sea level to elevations of $1,500 \mathrm{~m} \mathrm{[1].}$

Ecologically, black cherry provides services to support fauna, flora, and soil in the forest ecosystem. Especially in the early successional forest, black cherry provides habitat for small mammals such as rabbits, hares, squirrels, and mice [4]. The fruits of black cherry are an important source of mast for many mammals such as squirrels, deer, turkeys, bears, mice, and many bird species [3]. The tendency of black cherry to occupy a wide range of environments and fill disturbance gaps in the forest makes it an important stopover habitat for migrating birds [5]. In addition, black cherry is an important nectar and pollen resource for insects in forest ecosystems specifically in the early spring when other flowers are scarce [3]. Black cherry flowers are hermaphroditic (i.e., possessing both male and female reproductive organs) and selfincompatible (i.e., the inability of pollen fertilizing flowers on the same plant), and each flower ( $10 \mathrm{~mm}$ in diameter) has five small white petals [6]. These flowers are situated in clusters of 30-50 individuals on an inflorescence called a raceme (10-15 cm in length). The successfully cross-pollinated flowers produce a dark red to black drupe which contains a single seed. 
In the USA, the Allegheny Plateau in northwestern Pennsylvania is particularly well suited for the growth of high-quality black cherry $[1,3,7]$. However, land managers in the area have observed declining natural regeneration rates of black cherry since the end of the 20th century $[8,9]$. Although this decline could be caused by many factors such as stand age, deer browse, soil pathogens, ozone damage, or plant allelopathy [8,10-14], we have also observed a severe decline of fruit set in the area. This could be indicative of a pollination deficiency because the flowers are entomophilous and self-incompatible. The only published study involving black cherry pollinators was an observational study conducted by Robertson [15]. This study documented various flies, beetles, and bees visiting black cherry flowers in open-grown, landscape trees. In contrast, several studies suggested that honeybees and bumblebees are the primary pollinators of many other Prunus species in orchard settings [16]. However, there are no published data available on insects visiting black cherry flowers in forest ecosystems.

Thus, this study was conducted to characterize the insect assemblage associated with black cherry flowers and flower traits that can potentially shape the assemblage. The specific objectives of this study were: (1) to determine what insects visit the canopy and understory of black cherry stands before, during, and after the flowering period, (2) to identify whether insects caught in the canopy carry black cherry pollen, and (3) to characterize black cherry flower traits such as emitted volatile organic compounds (VOCs) that potentially contribute to the attraction of insects. Here we report for the first time on insects associated with flowering black cherry in a natural forest system.

\section{Results}

2.1. Survey and identification of insects visiting black cherry 
Overall, 9,533 arthropods were captured in 72 pan traps from two locations, three trees per location, and two trap positions (i.e., in the canopy and on the ground) per tree, three trapping periods (i.e., before, during, and after black cherry bloom) per trap, and two years (2018 and 2019). Major insect orders (98\% of all trap captures) were Diptera (flies), Coleoptera (beetles), Hymenoptera (bees and wasps), Lepidoptera (moths), and Thysanoptera (thrips) (Figure 1). Minor arthropods included Arachnida (spiders), Collembola (springtails), Trichoptera (caddisflies), Mecoptera (Scorpion flies), Orthoptera (grasshoppers and crickets), and Plecoptera (stoneflies). The proportions of major orders, unadjusted for trapping period and trap position, depended on the sampling year $\left(\chi^{2}=56.4, \mathrm{df}=5, \mathrm{p}<0.001\right)$, with a higher proportion of Diptera (70\%) in 2019 than in $2018(56 \%)$, but a lower proportion of Lepidoptera in $2019(4 \%)$ than in $2018(9 \%)$. However, proportions of insect orders and sampling sites were not related $(\mathrm{p}>0.05)$. In both trap locations across both years, Dipteran consistently comprised more than $60 \%$ of the assemblage, and Diptera and Coleoptera were two of the most abundant orders (Figure 1).

In the overall statistical model accounting for the sequence of flowering periods and repeated years with insect order as a random factor, we found higher captures of all arthropods in the canopy traps than on the ground $(\mathrm{F}=11.99, \mathrm{p}<0.001)$ but there were no differences in trap captures among three different trapping periods (i.e., before, during, and after flowering; Figure 2). Insect orders with significantly higher trap captures in the canopy traps than those in the ground traps were Diptera $(F=15.17, \mathrm{p}=0.0113)$, Lepidoptera $(\mathrm{F}=32.56, \mathrm{p}<0.001)$ and Thysanoptera $(\mathrm{F}=56.58, \mathrm{p}<0.001)$ (Figure 2$)$. By comparing trap captures in the canopy among three trapping periods, we found a significant effect of flowering period on trap captures of insects in Diptera $(\mathrm{F}=13.92, \mathrm{p}<0.001)$, Coleoptera $(\mathrm{F}=4.87, \mathrm{p}=0.02)$ and Lepidoptera $(\mathrm{F}=$ $7.1, \mathrm{p}=0.0037)$ 
Significant interaction of trap position and flowering period was detected in Diptera $(\mathrm{F}=5.54, \mathrm{p}$ $=0.012)$ and Hymenoptera $(F=7.32, p=0.004)($ Figure 3$)$. Specifically, Diptera counts in the canopy varied greatly with the flowering period; they were almost double in numbers during flowering comparing to before flowering $(\mathrm{t}=-5.88, \mathrm{p}<0.001)$, followed by a decline in numbers after flowering $(\mathrm{t}=3.92, \mathrm{p}<0.01)$. However, such a pattern was not observed in the trap captures on the ground (Figure 3). During the flowering period, traps in the canopy caught significantly more dipterans than those on the ground $(\mathrm{t}=5.13 ; \mathrm{p}<0.001)$.

Of the 5,655 insects captured in the canopy, the key insect species found during the flowering period were Anthalia bulbosa (Diptera: Hybotidae) which comprised 11\% of the total trap captures. Frankliniella spp. (Thysanoptera: Thripidae) were the second most abundant at $4 \%$. Rhamphomyia spp., (Diptera: Empididae), Athryglossa spp. (Diptera: Ephydridae), and Melanotus hyslopi (Coleoptera: Elateridae) comprised 3\%, 2\%, and 2\%, respectively (Table 1). The species with the next highest trap counts were Eusphalerum convexum (Coleoptera: Staphylinidae) and Melanolophia canadaria (Lepidoptera: Geometridae) which each comprised $\sim 1 \%$ of the total captures. Among these major insect species, A. bulbosa and Frankliniella spp. were captured significantly more in the canopy traps than in the ground traps (Table 1). 2.2. Characterization of insects carrying black cherry pollen The pollen grains of black cherry have a distinct morphology as was revealed by scanning electron microscopy (SEM) analysis. The pollen grains have a spheroidal shape with $42.13 \pm$ $0.58 \mu \mathrm{m}$ (polar) by $36.83 \pm 0.58 \mu \mathrm{m}$ (equatorial) dimensions (Figure $4 \mathrm{~d}$ ). The pollen grains were found to be isopolar and tricolpate, the pollen exine was tectate, and the sculpturing was striate (Figure 4d). 
Insects from three major orders (Coleoptera, Diptera, and Hymenoptera) representing 12 different families were collected from black cherry flowers for SEM analysis. Each of these insects was indeed observed to be carrying pollen grains on their body (Figure 5). Electron microscopy analysis showed that the pollen on these insects (Figures 4e-f \& 5) matched the size, shape, and exine texture of the pollen observed in the anthers of black cherry flowers (Figure 4d). A crane fly, Antocha sp. (Diptera: Limoniidae), was observed foraging on the flowers and was confirmed to be transporting black cherry pollen on the setae of the thorax (Figure 5a). Likewise, soldier beetles, Atalantycha bilineata (Coleoptera: Cantharidae), were observed foraging on the flowers and confirmed to be carrying pollen on their body (Figure 5b). All other collected insects, including the black carpenter ant, Camponotus pennsylvanicus (Hymenoptera: Formicidae), a weevil, Trichopion sp. (Coleoptera: Curculionidae), and fruit flies, Drosophila sp. (Diptera: Drosophilidae), were also found to be carrying black cherry pollen on their body, legs, and antennae (Figure 5c-e).

\subsection{Volatile profile of black cherry flowers}

Several flower characteristics including visual traits, such as flower morphology, arrangement, and pigmentation, as well as floral volatiles contribute to the attraction of pollinators. Visual traits can attract pollinators, especially when many individual flowers are arranged in larger inflorescences [17]. Individual black cherry flowers are only $\sim 10 \mathrm{~mm}$ in diameter and their corolla is made up of five white petals [6] (Figure 4b). However, black cherry flowers are arranged in clusters of 30-50 individual flowers (Figure 4a) on a 10-15cm long raceme [3,18]. In general, flowers emit complex and characteristic blends of volatile organic compounds (VOCs) into the surrounding atmosphere which enable the attraction of pollinators over large distances; 
however, also contribute to the defense against florivores and pathogens [19]. Our analysis of the volatile blend emitted from black cherry flowers revealed the existence of two different chemotypes among the trees in the Allegheny National Forest (Table 2, Figure S1). While 30 VOCs were emitted from flowers of both chemotypes, one and three compounds were found only in the floral volatile profile of chemotypes 1 and 2 , respectively. Of the 34 floral volatile compounds observed in total, the identity of 28 could be verified by comparison with authentic standards (Figures S2-6), and the remaining 6 compounds were tentatively identified by comparison of their mass spectra with the NIST library. The blend of volatiles emitted from black cherry flowers contained a number of monoterpenes (Table 2) with the two isomers, $(E)$ and $(Z)-\beta$-ocimene, together representing the most prominent of all detected volatile compounds (58.8\% and $71.0 \%$ of total VOCs in chemotype 1 and 2, respectively). Other less abundant monoterpene compounds found in the floral volatile blend include $\alpha$-pinene, $\alpha$-myrcene, Dlimonene, $\alpha$-linalool, (Z)-linalool oxide, and 3,4-dimethyl-2,4,6-octatriene (Table 2). In contrast to the abundance and diversity of monoterpenes, only minor amounts of one sesquiterpene, $(E, E)-\alpha$-farnesene, were emitted from black cherry flowers. Fatty acid derivatives are the second class of VOCs detected in the floral volatile profile of black cherry (Table 2) including the aldehydes nonanal and decanal, as well as the alkanes dodecane, tridecane, tetradecane, pentadecane, hexadecane, and heptadecane. The third major group of VOCs emitted from black cherry flowers are phenylpropanoids/benzenoids (Table 2) including phenylacetaldehyde and phenylethanol, as well as benzaldehyde, methyl salicylate, methyl benzoate, ethyl benzoate, and benzyl benzoate. While some of these compounds, such as benzaldehyde and phenylethanol, were produced in large quantities in flowers of chemotype 1, a different profile was observed for chemotype 2 . Flowers of chemotype 2 emitted three methoxylated derivatives, $p$-anisaldehyde 
(4-methoxybenzaldehyde), $p$-anisyl alcohol (4-methoxybenzyl alcohol), and methyl $p$-anisate (methyl 4-methoxybenzoate), which appear to be formed at the expense of some of the other phenylpropanoids/benzenoids that were absent (phenylacetaldehyde) or formed at lower quantities (phenylethanol, benzaldehyde, methyl benzoate, benzyl benzoate). In addition to compounds of the three major VOC classes, we also found one nitrogen-containing compound, methyl nicotinate, one sulfur-containing compound, benzothiazole, and linolenic acid derived (Z)-jasmone in the volatile profile emitted from black cherry flowers (Table 2).

There are a number of other important ornamental and fruit tree species in the genus Prunus. Since some of these Prunus species are highly dependent on pollinators for fruit production their floral volatile profiles have been studied previously [20-27] which allowed us to compare these with the profile observed here for black cherry (Table 2, Figure S1). Remarkably 27 of the 34 VOCs emitted from black cherry flowers were also found in the floral volatile profiles of at least one and often several other Prunus species (Table S1). The volatile compounds found in flowers of black cherry and other Prunus species belong to the three major classes terpenes, fatty acid derivatives and phenylpropanoids/benzenoids, including benzaldehyde which were present in all studied Prunus species (Table S1). By hierarchical clustering of their floral volatile profiles, expressed as the relative abundance of individual VOCs, the different Prunus species could be assigned to three groups (Figure 6) thus further highlighting their similarity. The first group contained several cultivars of the Chinese plum $(P$. mume), and their floral volatile profiles were dominated by some phenylpropanoids/benzenoids including eugenol, benzyl alcohol, and benzyl acetate, while the production of other VOCs was quite low. The second group contained various Prunus species, including cherry (P. avium), plum ( $P$. domestica), and peach ( $P$. persica), which are characterized by floral volatile profiles 
with the abundant formation of benzaldehyde and lilac aldehyde. The third group is composed of another set of $P$. mume cultivars and the two $P$. serotina chemotypes identified in this study and is characterized by $(E)$ - $\beta$-ocimene and benzaldehyde as the major compounds in their floral volatile profiles.

\section{Discussion}

The Rosaceae family consists of $\sim 100$ genera and more than 3,000 plant species worldwide [28]. The simple flowers in this family are considered generalists for attracting pollinators [29]. The genus Prunus, a member of Rosaceae [28], consists of 200 species, many of which are economically important as orchard crops [30], including cultivated almond, peach, plum, cherry, and apricot. Members of this genus typically bear five-petal flowers [31] which are self-incompatible and entomophilous. In orchards, $P$. salicina (Japanese plum) was shown to increase fruit production when managed bees were introduced to orchards [32]. Gyan and Woodell [33] analyzed pollen of P. spinosa (blackthorn) on Eristalis spp. (Diptera: Syrphidae), Bombus spp. (Hymenoptera: Apidae), and Apis mellifera (Hymenoptera: Apidae). They found that these insects transferred ample pollen to P. spinosa. When Osmia cornifrons (Hymenoptera: Megachilidae) are introduced to commercial sweet cherry ( $P$. avium) orchards the trees produce larger and heavier fruit [34]. The main insect species observed pollinating peach ( $P$. persica) is A. mellifera $[16,35]$. Chokecherry (P. virginiana) attracts bees in the genera of Andrena and Bombus, with noted observations of insects in Diptera visiting the flowers [36].

Our study conducted in the Allegheny National Forest showed a diverse assemblage of insects visiting the canopies of black cherry (Figure 1). Among this assemblage, Diptera was the most abundant group, and the dominant species collected were A. bulbosa, Rhamphomyia spp., 
Discocerina spp., and $P$. regina (Table 1). We also collected native bee species that are known to be pollinators of flowers including Auglochlora pura (Hymenoptera: Halictidae), Andrena carlini (Hymenoptera: Andrenidae), and Lasioglossum cressoni (Hymenoptera: Halictidae). However, Hymenoptera was found in significantly lower numbers compared to Diptera in our survey. This may suggest that they do not use the flowers as often as other species, or they were not efficiently captured by the pan traps. The moth species that was most prevalent in the canopy was Melanolophia canadaria (Lepidoptera: Geometridae) (Table 1). This species can feed on black cherry foliage as a caterpillar and has been demonstrated to carry pollen [37]. Two of the major beetle species observed in this study, M. hyslopi and E. convexum, have not been reported as pollinators or flower visitors previously. Anaspis rufa (Coleoptera: Scraptiidae) is known to feed on flowers and inhabits forest ecosystems [38], which could indicate a role of this species in pollination. Although flower thrips (Frankliniella spp.) were the second most abundant species collected in the canopy of black cherry (Table 1), they are generally considered as florivores [39] and it remains to be shown how much they contribute to pollination. Since small insects, such as some of those observed in the black cherry canopy, are poor flyers in general and could have trouble flying long distances and in windy conditions [40,41], these insects might only crosspollinate nearby black cherry trees.

Many angiosperms rely on insects to pollinate their flowers and thus use visual and olfactory flower cues to attract them. The flowers of Prunus species are similar in color and petal number, but their size and inflorescence structure are quite diverse. The flowers of black cherry are situated on racemes with 30-50 individual flowers (Figure 4) and are typically smaller ( 10 $\mathrm{mm})$ than those of other Prunus species including P. persica $(30-40 \mathrm{~mm})$, P. spinosa $(\sim 20 \mathrm{~mm})$, P. avium (30-40 mm), P. salicina $(25-50 \mathrm{~mm})$, and $P$. mume $(30-40 \mathrm{~mm})$ [42]. In addition, these 
trees only grow to around $10 \mathrm{~m}$ in height in an open-grown orchard setting, whereas black cherry can grow to 20-30 $\mathrm{m}$ in natural forests. P. virginiana has a flower size and raceme structure comparable to black cherry; however, it represents an understory woody plant and not a canopy species. P. padus is similar to black cherry in flower and stem size but not raceme structure. The flowers of $P$. padus (12-15 mm each in diameter) are arranged in groups of 3-7 per umbel and the bole can grow to a height of $19 \mathrm{~m}$ [43]. The pollinators of this species belong to six species of Diptera, two species of Hymenoptera, and four species of Coleoptera [43].

While visual cues are important for the attraction of pollinators, in particular, if flowers are arranged in inflorescences that contrast against the background, floral volatiles are also considered as a crucial long-distance signal in poorly lit habitats such as forest environments [44]. Our analysis revealed that black cherry flowers emit a volatile blend (Table 2, Figure 1) that is primarily composed of compounds belonging to the three major classes of floral volatiles, terpenes, phenylpropanoids/benzenoids, and fatty acid derivatives [19]. The majority of individual VOCs emitted from black cherry flowers (Table 2) have also been identified as floral volatiles in many other angiosperm families [45]. Remarkably, our comparison (Figure 6, Table S1) demonstrated that the black cherry floral volatile profile is very similar to that of other Prunus species which are highly dependent on pollinators for fruit production. It is well known that some VOCs found in floral volatile blends contribute to the attraction of pollinators, while others are involved in the defense against florivores and pathogens [19]. However, substantial evidence has emerged from previous studies that specific VOCs, which were also found in black cherry flowers in our study, are indeed involved in the attraction of different groups of pollinators. Several of the terpenes (e.g., (Z)- $\beta$-ocimene, $\alpha$-linalool, (Z)-linalool oxide, $\alpha$-pinene, (E,E)- $\alpha$-farnesene) and phenylpropanoids/benzenoids (e.g., phenylethanol, phenylacetaldehyde, 
methyl benzoate, methyl salicylate, p-anisaldehyde) emitted from black cherry flowers (Table 2) are known to be attractive to various bees (summarized in Dötterl \& Vereecken [44]). Likewise, plant species that attract lepidopterans for pollination specifically release phenylpropanoids/benzenoids (e.g., phenylethanol, phenylacetaldehyde) and terpenes (e.g., linalool, linalool oxides) [46-48], which are also prominent in the floral volatile profile of black cherry (Table 2). Additional behavioral tests with the flower-visiting butterflies Luehdorfia japonica (Lepidoptera: Papilionidae) and Pieris rapae (Lepidoptera: Pieridae) demonstrated that a group of VOCs including phenylacetaldehyde, phenylethanol, and benzaldehyde were highly attractive and elicited a respective response [25,49]. While black cherry flowers, like other Prunus species, clearly emit a blend of volatiles that should be attractive to Hymenoptera and Lepidoptera pollinators, surprisingly only relatively small numbers of these were observed in the canopy of black cherry trees in our survey (Figure 1). However, considering the similarly low numbers of Hymenoptera and Lepidoptera found in our ground traps (Figure 1) this appears to be due to an overall low abundance of these potential pollinators in the forest ecosystem, rather than to a lack of attraction to black cherry flowers. Although many insects in Diptera are considered as one of the most important groups of flower-visiting insects, which is in line with their high abundance in the canopy of black cherry trees observed in our surveys (Figure 1), our knowledge about their role in pollination and attraction to specific flower traits remains limited compared to the other major pollinators such as Hymenoptera and Lepidoptera. Similar to other pollinator insects, dipterans also use visual and olfactory cues to locate flowers. While some dipteran species appear to be specifically attracted to amine or sulfur-containing VOCs, many flowering plants visited by flies emit floral volatile blends that are devoid of these compounds and are rather composed of terpene, phenylpropanoid/benzenoid, and fatty acid derivative volatile 
compounds [50]. Recent analyses [51-53]) demonstrated that the antennae of flower-visiting syrphid flies are tuned to several phenylpropanoids/benzenoids (e.g., phenylacetaldehyde, phenylethanol, benzaldehyde, methyl benzoate, methyl salicylate, p-anisaldehyde) and terpenes (e.g., linalool, linalool oxides) which were all found in the floral volatile profile of black cherry (Table 2). Moreover, in field studies phenylethanol was found to be highly attractive to syrphid flies [54]. Since phenylethanol is abundant in black cherry flowers (Table 2), this suggests that this volatile compound could also contribute to the attraction of Diptera to the canopy of these trees.

In summary, this is the first report on the visitation of potential pollinators of black cherry in a natural forest ecosystem. Our data demonstrate that Diptera was the most frequently found insects in the canopy of black cherry during flowering. This suggests that these Diptera are attracted by the flower traits of black cherry, including visual traits as well as floral volatiles, and contribute to their pollination. However, due to the generalist morphology of the flowers and the similarity of the floral volatile profile to that of other Prunus species, it appears unlikely that a singular insect species or order, such as Diptera, is exclusively responsible for the crosspollination of black cherry flowers. Instead, successful cross-pollination of black cherry could depend on a wide variety of opportunistic nectar and pollen feeders. The results of our insect survey need to be considered in light of the general decline in abundance and diversity of pollinating insect populations over the last decades [55,56], which might explain the underrepresentation of particular insect orders in our trap captures. The small size and weak ability to fly of the two dominant insect species observed in our surveys, A. bulbosa and $F$. tritici, suggests that they might not represent very efficient cross-pollinators [41]. Instead, they might primarily transport pollen within the canopy of the same tree before other pollinators could 
bring pollen from a different black cherry tree, which would increase instances of geitonogamy and thus prevent successful seed production.

While our study provides baseline data on the insect assemblage associated with the canopy of flowering black cherry in a natural forest ecosystem, several questions remain that require future investigations. We did not measure the correlation between seed production and the abundance/absence of specific insect species or orders. Therefore, further studies are required to verify which insects are responsible for and how much they contribute to the cross-pollination of black cherry and seed production. Colored pan traps are a widely used method to sample flower-visiting insects, but this approach is potentially biased [57,58]. These traps tend to catch honeybees, bumblebees, and bees in the genus Colletes less frequently than expected by their perceived abundance [59]. This type of trap is also susceptible to damage caused by curious animals or certain weather conditions. Future studies with individual representative insect species performed under more controlled conditions could further verify their attraction to black cherry flowers and emitted volatiles, as well as their potential contribution to pollination. In addition, a possible decline in some pollinators (e.g., Hymenoptera, Lepidoptera) and the resulting shift in dominant insect species could explain the observed failure in fruit set and decreased natural regeneration of black cherry in recent years.

\section{Materials and Methods}

\subsection{Survey and identification of insects visiting black cherry}

A 2-year insect survey was conducted at two sites within the Allegheny National Forest in northwestern Pennsylvania, USA. The first site was located in Cherry Grove Township, Warren County (41.7238 N, -79.1242 W). The other site was $\sim 35 \mathrm{~km}$ east of Cherry Grove near 
Bradford (41.7475 N, -78.7665 W). The stands chosen at both sites were uneven-aged mixedspecies stands consisting of typical Allegheny hardwood species including hemlock (Tsuga Canadensis), American beech (Fagus grandifolia), maple (Acer spp.), and birch (Betula spp.). Each black cherry stand covers $\sim 12$ ha. Other vegetation in the stands includes raspberry (Rubus idaeus), blackberry (Rubus allegheniensis), partridgeberry (Mitella repens), Canada mayflower (Maianthemum canadensis), New York fern (Thelypteris noveborecensis), Trillium (Trillium spp.), trout lily (Erythronium americanum), ground pine (Lycopodium obsurum), and various grasses (Poa spp.).

To survey insect visitation to black cherry, we deployed colored pan traps from mid-May to early June in 2018 and 2019. We used pan traps for the insect survey because the canopy of black cherry formed 20-30 m above the ground, and physical access to the canopy for sampling pollinators visiting flowers by hand was impossible in the dense forest setting. Three subject trees were randomly chosen in each site, and two traps were deployed on each subject tree: one on the ground and one in the canopy. Each trap unit consisted of three 355-ml plastic cups (Solo, Lake Forest, IL, USA). Two of the cups were coated with fluorescent yellow and fluorescent blue paint, while the third cup was not pained, i.e., white (Figure S7a). The fluorescent pigmented paint (Fluorescent Blue and Yellow dispersion, Guerra Paint \& Pigment Corp., New York, NY, USA) was mixed with a water-based matte flexible acrylic polymer emulsion (Silica Flat, Guerra Paint \& Pigment Corp., New York, NY, USA). A solution of $25 \mathrm{~mL}$ unscented soap (Free and Clear Dish Soap, Seventh Generation, Burlington, VT, USA) per 3.8 liters of water was used to fill the cups [60]. These three colors and the trap design have been shown to attract different orders of insects [61,62]. The canopy traps consisting of the three cups placed on a platform made from plastic pail lids and were hung in the crown of selected black cherry trees 
using a slingshot (Big Shot Slingshot, Sherrill Tree, Greensboro, NC, USA) and paracord rope (Figure S7b-c). For comparison with the trap captures in the canopy, the ground traps were positioned directly below the canopy traps and placed on $30-\mathrm{cm}$ wooden stakes. The insects caught in the traps were strained from the soap solution using a fine mesh paint strainer and stored in sample bags with $70 \%$ ethanol. All insect samples were sorted and identified to family and morphospecies by using a stereomicroscope (Olympus SZ71, Olympus Inc., Tokyo, Japan) equipped with a digital camera (Olympus DP21, Cell Sens Dimension, Olympus Inc., Tokyo, Japan). Major insect species found in the samples were further identified to species with the help of insect taxonomists: Robert Acciavatti (Coleoptera), Andrea Kautz (Diptera), Sam Droege (Hymenoptera), and Gwan-Seok Lee (Thysanoptera).

For data analysis trap captures from the three colored cups were combined and treated as a single trap unit. Trap counts were normalized by dividing total captures by days of trap deployment. Lack of normal distribution of residuals on normalized averaged trap counts was compensated by taking the square root of normalized averaged counts (i.e., $\sqrt{x+0.0001}$ ). Three separate statistical analyses were conducted to determine the effects of trap location and flowering period on trap capture. First, the proportions of trap captures among insect orders were analyzed by Cochran-Mantel-Haenszel $(\mathrm{CMH})$ frequency analysis that tested whether or not insect orders were related to the trap position (i.e., ground and canopy), flowering periods (i.e., before, during, and after flowering), years (i.e., 2018 and 2019) and sampling sites (i.e., Bradford and Cherry Grove sites). Second, effects of trap positions, flowering periods, and sampling years, and their interactions on trap captures were analyzed across all insect orders using doubly repeated measures ANOVA [63]. Repeated factors were the year and flowering period, by using unstructured and compound symmetry covariance structure, respectively. The insect order was 
used as a random effect and least-square means were compared using Tukey-Kramer adjustment. Individual analyses for specific insect orders were also conducted using doubly repeated measures ANOVA as described above. Lastly, the effect of the trap position on counts of major insect species during the flowering period was examined using the Wilcoxon (rank sums) test followed by Chi-Square approximation. All the data analyses were conducted with SAS 9.4. and JMP Pro 14.0 [64], and significance criterion $\alpha$ for all tests was 0.05 .

\subsection{Characterization of insects carrying black cherry pollen}

To determine whether insects visiting black cherry carried its pollen, we collected additional insect samples and black cherry flowers from a site in Morgantown, WV, USA (39.6465 N, -79.8794 W). For pollen sampling, a black cherry tree with a widespread canopy easily assessable from the ground was selected. Five branches with flower buds were cut from the tree before the onset of anthesis and immediately placed in a bucket with water. To capture flower visitors, a 50-mL centrifuge tube was carefully placed over insects visiting the flowers. Both insect and flower samples were transported to the laboratory for further observation and analysis.

To characterize black cherry pollen morphology, sampled flowers were observed until anthers opened to release pollen. The newly opened anthers were removed and coated with gold (200-400 Å in thickness) using a Denton Desk V sputter coater (Dentonvacuum LLC) [65]. The morphology of black cherry pollen and its exine structure were examined using SEM (S-4700, Hitachi, Tokyo, Japan) at the Shared Research Facilities of West Virginia University, and photographed with the SEM beam condition set at $5.0 \mathrm{kV}$ and $10 \mu \mathrm{A}$. The SEM images were used to determine the shape, size, and exine structure of the pollen grains. The insects collected 
from black cherry flowers were prepared and analyzed by SEM using the protocol described above. The morphological characteristics and exine structure of pollen grains found on these insects were then compared to those of pollen grains collected from the anthers of black cherry flowers.

\subsection{Collection and analysis of floral volatiles}

Branches from black cherry trees located in the Allegheny National Forest were sampled during full anthesis. Cut branches were placed into a water-filled container and kept at a stable temperature for transport. Volatiles emitted from black cherry flowers were collected using a closed-loop stripping method as described previously [66,67]. Five racemes or sections of racemes with open flowers were cut from freshly harvested branches for each volatile collection. Headspace collections from detached racemes supplemented with $20 \%$ (w/v) sucrose solution were performed for 24 hours using Porapak-Q traps (Volatile Collection Trap LLC, Gainesville, FL, USA). Subsequently the Porapak-Q traps were eluted with dichloromethane and $3.33 \mu \mathrm{g}$ of naphthalene was added as internal standard.

Samples from headspace collections were analyzed by combined gas chromatography/mass spectrometry (GC/MS) using a TRACE 1310 gas chromatograph system linked to a TSQ 8000 Triple Quadrupole mass spectrometer (Thermo Fisher Scientific, Waltham, MA, USA) as described previously [66,67]. Individual compounds were identified using the Xcalibur 2.2 SP1.48 software (Thermo Fisher Scientific) by comparing their mass spectra with those deposited in the NIST/EPA/NIH Mass Spectral Library (NIST11) (National Institute of Standards and Technology NIST, Scientific Instrument Services, Inc., NJ, USA; https://chemdata.nist.gov/mass-spc/ms-search/). The identity of compounds was confirmed by 
comparison of retention times and mass spectra with authentic standards (Table S2). These standards also allowed determination of response factors, which were used in combination with the internal standard for the quantification of analyzed compounds.

We also investigated how the profile of volatiles emitted from black cherry flowers differs from respective profiles described previously for closely related Prunus species [21-24,27]. The quantities of the floral volatile compounds in each Prunus species were converted to percentages, and their major volatile compounds emitted (>4\%) were assembled in a database. Subsequently, the profiles were all normalized by "shifted log" transformation, compared by a hierarchical clustering analysis (Ward's minimum variance method), and visualized by a "Heatmap" function in “ComplexHeatmap" package [68] in R 3.6.3.

Supplementary Materials: The following are available online at www.mdpi.com/xxx/s1, Figure S1: Characterization of the profile of volatile organic compounds emitted from black cherry flowers. Volatiles were analyzed by GC/MS, and total ion chromatograms are shown for both chemotypes. Compounds were identified based on their mass spectra and retention time: 1 - 34, see Table 2 for compound identity; IS, internal standard (naphthalene), Figure S2: Confirmation of VOC identity by comparison of volatiles emitted from black cherry flowers with authentic terpene standards. Volatiles and standards were analyzed by GC/MS, and total ion chromatograms are shown for: floral volatiles (A \& H), $\alpha$-pinene (B), $\alpha$-myrcene (C), Dlimonene (D), ocimene isomers (E), linalool oxide isomers (F), $\alpha$-linalool $(\mathrm{G})$, farnesene isomers (I), Figure S3: Confirmation of VOC identity by comparison of volatiles emitted from black cherry flowers with authentic phenylpropanoid/benzenoid standards. Volatiles and standards were analyzed by GC/MS, and total ion chromatograms are shown for: floral volatiles (A \& G), 
benzaldehyde (B), phenylacetaldehyde (C), methyl benzoate (D), phenylethanol (E), ethyl benzoate $(\mathrm{F})$, benzyl benzoate $(\mathrm{H})$, Figure S4: Confirmation of VOC identity by comparison of volatiles emitted from black cherry flowers with authentic standards of methoxylated aromatic compounds. Volatiles and standards were analyzed by GC/MS, and total ion chromatograms are shown for: floral volatiles (A), $p$-anisaldehyde (B), $p$-anisyl alcohol (C), methyl $p$-anisate (D), Figure S5: Confirmation of VOC identity by comparison of volatiles emitted from black cherry flowers with authentic standards of fatty acid derivative compounds. Volatiles and standards were analyzed by GC/MS, and total ion chromatograms are shown for: floral volatiles (A), nonanal (B), hexadecane (C), alkane standard C8 - C20 (D), Figure S6: Confirmation of VOC

identity by comparison of volatiles emitted from black cherry flowers with authentic standards of other volatile compounds. Volatiles and standards were analyzed by GC/MS, and total ion chromatograms are shown for: floral volatiles (A), methyl nicotinate (B), methyl salicylate (C), benzothiazole (D), (Z)-jasmone (E), Figure S7: Ground (a) and aerial (b and c) pan traps with three different colors: white, blue, and yellow, Table S1: Floral volatiles identified in Prunus serotina and other Prunus species, Table S2: Volatile organic compounds used as authentic standards for the verification and quantification of compounds observed in black cherry flowers.

\section{References}

1. Hough, A.F. Silvical characteristics of black cherry (Prunus serotina). Northeastern Forest Experiment Station, Station Paper No 139, USDA Forest Service, Upper Darby, PA, USA, 1960. 
2. McVaugh, R. A revision of the North American black cherries (Prunus serotina Ehrh and Relatives). Brittonia 1951, 7, 279-315.

3. Marquis, D.A., Prunus serotina Ehrh. black cherry. Silvics of North America 1990, 2, 594-604.

4. Litvaitis, J.A., Importance of early successional habitats to mammals in eastern forests. Wildlife Society Bulletin 2001, 29, 466-473.

5. Rodewald P.G.; Brittingham, M.C., Stopover habitats of landbirds during fall: use of edge-dominated and early-successional forests. The Auk 2004, 121, 1040-1055.

6. Forbes, D.C. Self-and cross-incompatibility in black cherry (Prunus serotina). University of Florida Doctoral Dissertation. Gainesville, FL, USA, 1969.

7. Whitney, G.G. The history and status of the hemlock-hardwood forests of the Allegheny Plateau. Journal of Ecology 1990, 78, 443-458.

8. Long, R.P.; Ristau, T.E. Changes in Black Cherry Seed Production: Is Stand Age a Factor? Northeastern Naturalist 2020, 2, 281-298.

9. Stout, S.L.; Brose, P.H.; Cleveland, H.; Long, R.P.; McGuinness, B.; Peters, M.P.; Rebbeck, J.; Ristau, T.; Royo, A.A.; Stoleson, S. H.; Thomasma, S.; Twery, M.J.; Wurzbacher, S. Fifty years of science-management cooperation from the SILVAH community of practice. In Proceedings of the Allegheny Society of American Foresters training session; S. L. Stout Ed. Newtown Square, PA, USDA Forest Service, 2019, pp. $8-25$.

10. Horsley, S.B. Role of allelopathy in hay-scented fern interference with black cherry regeneration. Journal of Chemical Ecology 1993, 19, 2737-2755. 
11. Lee, J.C.; Skelly, J.M.; Steiner K.C.; Zhang, J.W.; Savage, J.E. Foliar response of black cherry (Prunus serotina) clones to ambient ozone exposure in central Pennsylvania. Environmental Pollution 1999, 105, 325-331.

12. Marquis, D.A.; Gearhart, P. Cherry-maple: Silvicultural systems for the major forest types of the United States. Agricultural Handbook 1983, 445, 137-140.

13. Packer, A.; Clay, K.J. Soil pathogens and spatial patterns of seedling mortality in a temperate tree. Nature 2000, 404, 278-281.

14. Packer, A.; Clay, K.J. Development of negative feedback during successive growth cycles of black cherry. The Royal Society, 2004, 271, 317-324.

15. Robertson, C. Flowers and insects: Rosaceae and Compositae. Academy of Science of St. Louis., St. Louis, MO, USA,1894.

16. Chaudhary, O.P. Influence of different colony placement distances on yield and quality parameters of peach (Prunus persica L.). Korean Journal of Apiculture 2008, 23, 89-95.

17. Giurfa, M.; Vorobyev, M.; Kevan, P.; Menzel, R. Detection of coloured stimuli by honeybees: minimum visual angles and receptor specific contrasts. Journal of Comparative Physiology A 1996, 178, 699-709.

18. Pairon, M.; Petitpierre, B.; Campbell, M.; Guisan, A.; Broennimann, O.; Baret, P.V.; Jacquemart, A.L.; Besnard, G. Multiple introductions boosted genetic diversity in the invasive range of black cherry (Prunus serotina; Rosaceae), Annals of Botany 2010, 105, 881-890.

19. Muhlemann, J.K.; Klempien, A.; Dudareva, N. Floral volatiles: from biosynthesis to function. Plant, Cell and Environment 2014, 37, 1936-1949. 
20. Radulovic, N.S.; Dordevic, A.S.; Zlatkovic, B.K.; Palic, R.M. GC-MS analyses of flower ether extracts of Prunus domestica L. and Prunus padus L. (Rosaceae). Chemical Papers $2009,63,377-384$.

21. Hao, R.; Du, D.; Wang, T.; Yang, W.; Wang, J.; Zhang, Q. A comparative analysis of characteristic floral scent compounds in Prunus mume and related species. Bioscience, Biotechnology, and Biochemistry 2014, 78, 1640-1647.

22. El-Sayed, A.M.; Sporle, A.; Colhoun, K.; Furlong, J.; White, R.; Suckling, D.M. Scents in orchards: floral volatiles of four stone fruit crops and their attractiveness to pollinators. Chemoecology 2018, 28, 39-49.

23. Reidel, R.V.B.; Cioni, P.L.; Pistelli, L. Volatile emission of different plant parts and fruit development from Italian cherry plums (Prunus cerasifera and P. cerasifera 'Pissardii'). Biochemical Systematics and Ecology 2017, 75, 10-17.

24. Zhang, T.; Bao, F.; Yang, Y.; Hu, L.; Ding, A.; Ding, A.; Wang, J.; Cheng, T.; Zhang, Q. A comparative analysis of floral scent compounds in intraspecific cultivars of Prunus mume with different corolla colours. Molecules 2020, 25, 145.

25. Omura, H.; Honda, K.; Nakagawa, A.; Hayashi, N. The role of floral scent of the cherry tree, Prunus yedoensis, in the foraging behavior of Luehdorfia japonica (Lepidoptera: Papilionidae). Applied Entomology and Zoology 1999, 34, 309-313.

26. Mastelic, J.; Jerkovic, I.; Mesic, M. Volatile constituents from flowers, leaves, bark and wood of Prunus mahaleb L. Flavour and Fragrance Journal 2006, 21, 306-313.

27. Kang, W.; Xu, Q. Rapid determination of volatile constituents from the buds and flowers of Prunus Persica (L.) Batsch. f. duplex Rehd. 2nd International Conference on Bioinformatics and Biomedical Engineering, Shanghai, 2008, pp. 1024-1027. 
28. Gilani, S.A.; Qureshi, R.A.; Khan, A.M.; Potter, D. A molecular phylogeny of selected species of genus Prunus L. (Rosaceae) from Pakistan using the internal transcribed spacer (ITS) spacer DNA. African Journal of Biotechnology 2010, 9, 4867-4872.

29. Ollerton, J.; Killick, A.; Lamborn, E.; Watts, S.; Whiston, M. Multiple meanings and modes: on the many ways to be a generalist flower. Taxon 2007, 56, 717-728.

30. Lee, S.; Wen, J. A phylogenetic analysis of Prunus and the Amygdaloideae (Rosaceae) using ITS sequences of nuclear ribosomal DNA. American Journal of Botany 2001, 88, 150-160.

31. Sytsma, K.J. Rosaceae. Encyclopedia Britannica. Retrieved from https://www.britannica.com/plant/Rosaceae, 2016.

32. Calzoni, G.L.; Speranza A. Insect controlled pollination in Japanese plum (Prunus salicina Lindl.). Scientia Horticulturae 1998, 72, 227-237.

33. Gyan, K.Y.; Woodell, S.R.J. Analysis of insect pollen loads and pollination efficiency of some common insect visitors of four species of woody Rosaceae. Functional Ecology $1987,1,269-274$.

34. Ryder, J.T.; Cherrill, A.; Prew, R.; Shaw, J.; Thorbek, P.; Walters, K.F. Impact of enhanced Osmia bicornis (Hymenoptera: Megachilidae) populations on pollination and fruit quality in commercial sweet cherry (Prunus avium L.) orchards. Journal of Apicultural Research 2020, 59, 77-87.

35. Thapa, R.B. Honeybees and other insect pollinators of cultivated plants: a review. Journal of the institute of Agriculture and Animal Science 2006, 27, 1-23. 
36. Suarez-Gonzalez, A.; Good, S.V. Pollen limitation and reduced reproductive success are associated with local genetic effects in Prunus virginiana, a widely distributed selfincompatible shrub. Annals of Botany 2013, 113, 595-605.

37. LeCroy, K.A.; Shew, H.W.;van Zandt, P.A. Pollen presence on nocturnal moths in the Ketona Dolomite glades of Bibb County, Alabama. Southern Lepidopterists' News 2013, $35,136-142$.

38. Frost, S.W. A preliminary study of North American insects associated with elderberry flowers. Florida Entomologist 1979, 341-355.

39. Kirk, W.D.J. Pollen-feeding in thrips (Insecta: Thysanoptera). Journal of Zoology 1984, 204, 107-117.

40. Bernays, E.A.; Chapman, R.F. Host-plant selection by phytophagous insects. Springer Science \& Business Media, Berlin, Germany, 2007.

41. Lewis, T. Feeding, flight and dispersal in thrips. Towards understanding Thysanoptera. USDA Northeastern Forest Experimental Station General. Technical Report NE-147, 1991, 63-70.

42. USDA NRCS. The PLANTS Database. Retrieved from http://plants.usda.gov, 2021.

43. Leather, S. R. Prunus Padus L. Journal of Ecology 1996, 84, 125-132.

44. Dötterl, S.; Vereecken, N.J. The chemical ecology and evolution of bee-flower interactions: a review and perspectives. Canadian Journal of Zoology 2010, 88, 668-697.

45. Schiestl, F.P. The evolution of floral scent and insect chemical communication. Ecology Letters 2010, 13, 643-656. 
46. Knudsen, J.T.; Tollsten, L. Trends in floral scent chemistry in pollination syndromes: floral scent composition in moth-pollinated taxa. Botanical Journal of the Linnean Society 1993, 113, 263-284.

47. Andersson, S.; Nilsson, L.A.; Groth, I.; Bergström, G. Floral scents in butterflypollinated plants: possible convergence in chemical composition. Botanical Journal of the Linnean Society, 2002, 140, 129-153.

48. Dobson, H.E.M. Relationship between floral fragrance composition and type of pollinator. In Biology of Floral Scent; Dudareva, N. ; Pichersky E., Eds. CRC Press, Boca Raton, FL, USA, 2006, pp. 147- 198.

49. Honda, K.; Omura, H.; Hayashi, N. Identification of floral volatiles from Ligustrum japonicum that stimulate flower-visiting by cabbage butterfly, Pieris rapae. Journal of Chemical Ecology 1998, 24, 2167-2180.

50. Woodcock, T.S; Larson, B.M.H.; Kevan, P.G.; Imouye, D.W.; Lunau, K. Flies and flowers II: floral attractants and rewards. Journal of Pollination Ecology 2014, 12, 63 94.

51. Primate, C.; Dötterl, S. A syrphid fly uses olfactory cues to find a non-yellow flower. Journal of Chemical Ecology 2010, 36, 1207-1210.

52. Braunschmid, H.; Mükisch, B.; Rupp, T.; Schäffler, I.; Zito, P.; Birtele, D.; Dötterl, S. Interpopulation variation in pollinators and floral scent of the lady's-slipper orchid Cypripedium calceolus L. Arthropod-Plant Interactions 2017, 11, 363-379.

53. Li, H.M.; Liu, W.B.; Yang, L.L.; Cao, H.Q.; Pelosi, P.; Wang, G.R.; Wang, B. Aromatic volatiles and odorant receptor 25 mediate attraction of Eupeodes corollae to flowers. Journal of Agricultural and Food Chemistry 2020, 68, 12212-12220. 
54. Zhu, J.; Park, K.C. Methyl salicylate, a soybean aphid-induced plant volatile attractive to the predator Coccinella septepunctata. Journal of Chemical Ecology 2005, 31, 1733 1746.

55. Biesmeijer, J.C.; Roberts, S.P.M.; Reemer, M.; Ohlemüller, R.; Edwards, M.; Peeters, T.; Schaffers, A.P.; Potts, S.G.; Kleukers, R.; Thomas, C.D.; Settele, J.; Kunin, W.E. Parallel declines in pollinators and insect-pollinated plants in Britain and the Netherlands. Science 2006, 313, 351-354.

56. Powney, G.D.; Carvell, C.; Edwards, M.; Morris, R.K.A.; Roy, H.E.; Woodcock, B.A.; Nick J.B. Isaac, N.J.B. Widespread losses of pollinating insects in Britain. Nature Communications 2019, 10, 1018.

57. Baum, K.A.; Wallen, K.E. Potential bias in pan trapping as a function of floral abundance. Journal of the Kansas Entomological Society 2011, 84, 155-159.

58. Vrdoljak, S.M.; Samways, M.J. Optimising coloured pan traps to survey flower visiting insects. Journal of Insect Conservation 2012, 16, 345-354.

59. Roulston, T.H.; Smith, S.S.; Brewster. A.L. A comparison of pan trap and intensive net sampling techniques for documenting a bee (Hymenoptera: Apiformes) fauna. Journal of the Kansas Entomological Society 2007, 80, 179-181.

60. Droege, S. Handy Bee Manual. USGS Native Bee Inventory and Monitoring Lab, Beltsville, MD, USA, 2012.

61. Droege, S. Impact of color and size of bowl trap on numbers of bees captured. Retrieved from http://online.sfsu.edu/beeplot/pdfs/color\%20and\%20size.pdf, 2006. 
62. Nuttman, C.V.; Otieno, M.; Kwapong, P.K.; Combey, R.; Willmer, P.; Potts, S.G. The utility of aerial pan-trapping for assessing insect pollinators across vertical strata. Journal of the Kansas Entomological Society 2011, 4, 260-270.

63. Gbur E.E. Analysis of generalized linear mixed models in the agricultural and natural resources sciences. American Society of Agronomy, Soil Science Society of America, Crop Science Society of America, Madison, WI, USA, 2012.

64. SAS Institute Inc. SAS/STAT. ®. 9.4 User's. Guide. SAS Institute Inc., Cary, NC, USA, 2019.

65. Hafner, B. Scanning electron microscopy primer. Characterization Facility, University of Minnesota, Twin Cities, MN, USA, 2007.

66. Wang, F.; Park, Y.-L.; Gutensohn, M. Glandular trichome-derived sesquiterpenes of wild tomato accessions (Solanum habrochaites) affect aphid performance and feeding behavior. Phytochemistry 2020, 180, 112532.

67. Wang, F.; Park, Y.-L.; Gutensohn, M. Glandular trichome-derived mono-and sesquiterpenes of tomato have contrasting roles in the interaction with the potato aphid Macrosiphum euphorbiae. Journal of Chemical Ecology 2021, 47, 204-214.

68. Gu, Z.; Eils, R.; Schlesner, M. Complex heatmaps reveal patterns and correlations in multidimensional genomic data. Bioinformatics 2016, 32, 2847-2849. 
Table 1. Major insect species captured per day $( \pm \mathrm{SE})$ in the canopy and ground traps during the flowering period $(\alpha=0.05 ; *, \mathrm{p}<0.05 ; * *, \mathrm{p}<0.01)$.

\begin{tabular}{lllllll}
\hline Order & Family & Species & Canopy & Ground & $\chi^{2}$ & p value \\
\hline Diptera & Hybotidae & Anthalia bulbosa & $109.7 \pm 1.9$ & $31.5 \pm 1.6$ & 7.2445 & $0.0071 * *$ \\
Thysanoptera & Thripidae & Frankliniella spp. & $40.2 \pm 0.6$ & $6.2 \pm 0.4$ & 4.083 & $0.0433 *$ \\
Diptera & Empididae & Rhamphomyia spp. & $30.4 \pm 1.1$ & $11.3 \pm 0.7$ & 1.899 & 0.1682 \\
Diptera & Ephydridae & Discocerina spp. & $20.8 \pm 1.0$ & $1.7 \pm 0.3$ & 1.547 & 0.2136 \\
Coleoptera & Elateridae & Melanotus hyslopi & $16.5 \pm 0.4$ & $1.4 \pm 0.1$ & 0.7259 & 0.3942 \\
Coleoptera & Staphylinidae & Eusphalerum convexum & $14.5 \pm 1.3$ & $0.9 \pm 0.1$ & 1.0891 & 0.2967 \\
Lepidoptera & Geometridae & Melanolophia canadaria & $9.14 \pm 0.9$ & $0.7 \pm 0$ & 3.3251 & 0.0682 \\
Coleoptera & Scraptiidae & Anaspis rufa & $8.4 \pm 0.3$ & $1 \pm 0.1$ & 1.1136 & 0.2913 \\
Hymenoptera & Halictidae & Auglochlora spp. & $5.7 \pm 0.1$ & $3.5 \pm 0.2$ & 1.7526 & 0.1855 \\
Coleoptera & Chrysomelidae Crepidodera violacea & $4.3 \pm 0.2$ & $0.6 \pm 0$ & 1.3125 & 0.2519 \\
Diptera & Calliphoridae & Phormia regina & $3.4 \pm 0.1$ & $0.1 \pm 0$ & 0.3333 & 0.5637 \\
\hline
\end{tabular}


Table 2. Volatile organic compounds identified in the headspace of Prunus serotina flowers

\begin{tabular}{|c|c|c|c|c|c|c|}
\hline \multirow{2}{*}{\multicolumn{2}{|c|}{ Compound $^{1}$}} & \multirow{2}{*}{ CAS } & \multirow{2}{*}{$\begin{array}{l}\text { NIST } \\
\mathrm{RI}^{2}\end{array}$} & \multirow{2}{*}{$\begin{array}{l}\text { Exp } \\
\mathrm{RI}^{3}\end{array}$} & Chemotype 1 & Chemotype 2 \\
\hline & & & & & \multicolumn{2}{|c|}{$\mathrm{pmol} /$ flower $/ \mathrm{hr}($ mean $\pm \mathrm{SE}, \mathrm{n}=5)$} \\
\hline 1 & $\alpha$-Pinene & $80-56-8$ & 937 & 935 & $0.24 \pm 0.1$ & $1.3 \pm 0.69$ \\
\hline 2 & Benzaldehyde & $100-52-7$ & 962 & 962 & $161.21 \pm 37.4$ & $4.27 \pm 0.62$ \\
\hline 3 & $\alpha$-Myrcene & $123-35-3$ & 991 & 993 & $3.16 \pm 0.38$ & $2.23 \pm 0.34$ \\
\hline 4 & D-Limonene & $138-86-3$ & 1030 & 1031 & $10.75 \pm 2.41$ & $3.19 \pm 0.6$ \\
\hline 5 & $(Z)-\beta$-Ocimene & $3338-55-4$ & 1038 & 1041 & $56.88 \pm 8.41$ & $31.23 \pm 7.14$ \\
\hline 6 & Phenylacetaldehyde & $122-78-1$ & 1045 & 1047 & $15.49 \pm 3.19$ & - \\
\hline 7 & $(E)$ - $\beta$-Ocimene & $3779-61-1$ & 1049 & 1054 & $415.91 \pm 67.99$ & $230.1 \pm 43.54$ \\
\hline 8 & (Z)-Linalool oxide & $5989-33-3$ & 1074 & 1090 & $0.7 \pm 0.16$ & $1.54 \pm 0.97$ \\
\hline 9 & Methyl benzoate & $93-58-3$ & 1094 & 1098 & $13.73 \pm 2.25$ & $3.5 \pm 1.86$ \\
\hline 10 & $\alpha$-Linalool & $78-70-6$ & 1099 & 1104 & $4.59 \pm 0.52$ & $3.36 \pm 1.08$ \\
\hline 11 & Nonanal & $124-19-6$ & 1104 & 1107 & $1.46 \pm 0.35$ & $2.65 \pm 1.26$ \\
\hline 12 & Phenylethanol & $60-12-8$ & 1116 & 1119 & $71.51 \pm 10.02$ & $15.66 \pm 3.47$ \\
\hline 13 & 3,4-Dimethyl-2,4,6-octatriene & $57396-75-5$ & 1121 & 1132 & $0.98 \pm 0.23$ & $0.11 \pm 0.11$ \\
\hline 14 & Methyl nicotinate & $93-60-7$ & 1139 & 1142 & $3.33 \pm 0.78$ & $13.31 \pm 2.69$ \\
\hline 15 & Ethyl benzoate & $93-89-0$ & 1171 & 1175 & $2.91 \pm 0.41$ & $1.18 \pm 0.33$ \\
\hline 16 & Methyl salicylate & $119-36-8$ & 1192 & 1199 & $2.75 \pm 0.2$ & $0.12 \pm 0.12$ \\
\hline 17 & Dodecane & $112-40-3$ & 1200 & 1200 & $0.02 \pm 0.02$ & $2.07 \pm 1.05$ \\
\hline 18 & Decanal & $112-31-2$ & 1206 & 1209 & $0.71 \pm 0.17$ & $0.86 \pm 0.3$ \\
\hline 19 & $N$-Phenylformamide & $103-70-8$ & 1221 & 1225 & $6.1 \pm 2.13$ & $6.56 \pm 1.36$ \\
\hline 20 & Benzothiazole & $95-16-9$ & 1229 & 1232 & $4.79 \pm 1.53$ & $6.55 \pm 1.47$ \\
\hline 21 & $p$-Anisaldehyde & $123-11-5$ & 1250 & 1264 & - & $14.73 \pm 3.23$ \\
\hline 22 & $p$-Anisyl alcohol & $105-13-5$ & 1290 & 1293 & - & $6.89 \pm 1.92$ \\
\hline 23 & Tridecane & $629-50-5$ & 1300 & 1300 & $0.39 \pm 0.09$ & $1.66 \pm 0.86$ \\
\hline 24 & $N, N$-Dibutylformamide & $761-65-9$ & 1310 & 1308 & $0.54 \pm 0.08$ & $0.56 \pm 0.13$ \\
\hline 25 & Texanol & $77-68-9$ & 1380 & 1381 & $0.76 \pm 0.15$ & $1.82 \pm 0.97$ \\
\hline 26 & Methyl $p$-anisate & $121-98-2$ & 1373 & 1383 & - & $3.36 \pm 0.64$ \\
\hline 27 & Tetradecane & $629-59-4$ & 1400 & 1400 & $0.52 \pm 0.12$ & $0.78 \pm 0.3$ \\
\hline 28 & (Z)-Jasmone & $488-10-8$ & 1394 & 1406 & $7.93 \pm 1.42$ & $3.18 \pm 0.82$ \\
\hline 29 & Pentadecane & $629-62-9$ & 1500 & 1500 & $0.7 \pm 0.22$ & $0.35 \pm 0.05$ \\
\hline 30 & $(E, E)-\alpha$-Farnesene & $502-61-4$ & 1508 & 1514 & $4.97 \pm 0.53$ & $0.95 \pm 0.22$ \\
\hline 31 & $\begin{array}{l}\text { Hexadecane } \\
\text { 4-sec-Butyl-2,6-di-tert- }\end{array}$ & $544-76-3$ & 1600 & 1600 & $1.21 \pm 0.37$ & $1.94 \pm 0.62$ \\
\hline 32 & butylphenol & $17540-75-9$ & 1640 & 1650 & $6.91 \pm 3.06$ & $1.32 \pm 0.9$ \\
\hline 33 & Heptadecane & $629-78-7$ & 1700 & 1700 & $0.98 \pm 0.24$ & $0.62 \pm 0.12$ \\
\hline 34 & Benzyl benzoate & $120-51-4$ & 1762 & 1789 & $2.24 \pm 0.45$ & $0.16 \pm 0.13$ \\
\hline
\end{tabular}

${ }^{1}$ Compounds highlighted in italic are only identified by comparison of mass spectra with the NIST library.

${ }^{2}$ Median values of retention indices for semi-standard non-polar columns (obtained from NIST/EPA/NIH MS library version 2.2).

${ }^{3}$ Experimental retention indices relative to C8-C24 n-alkane standards on TraceGOLD TG-5MS GC column according to the Van den Dool-Kratz equation. 


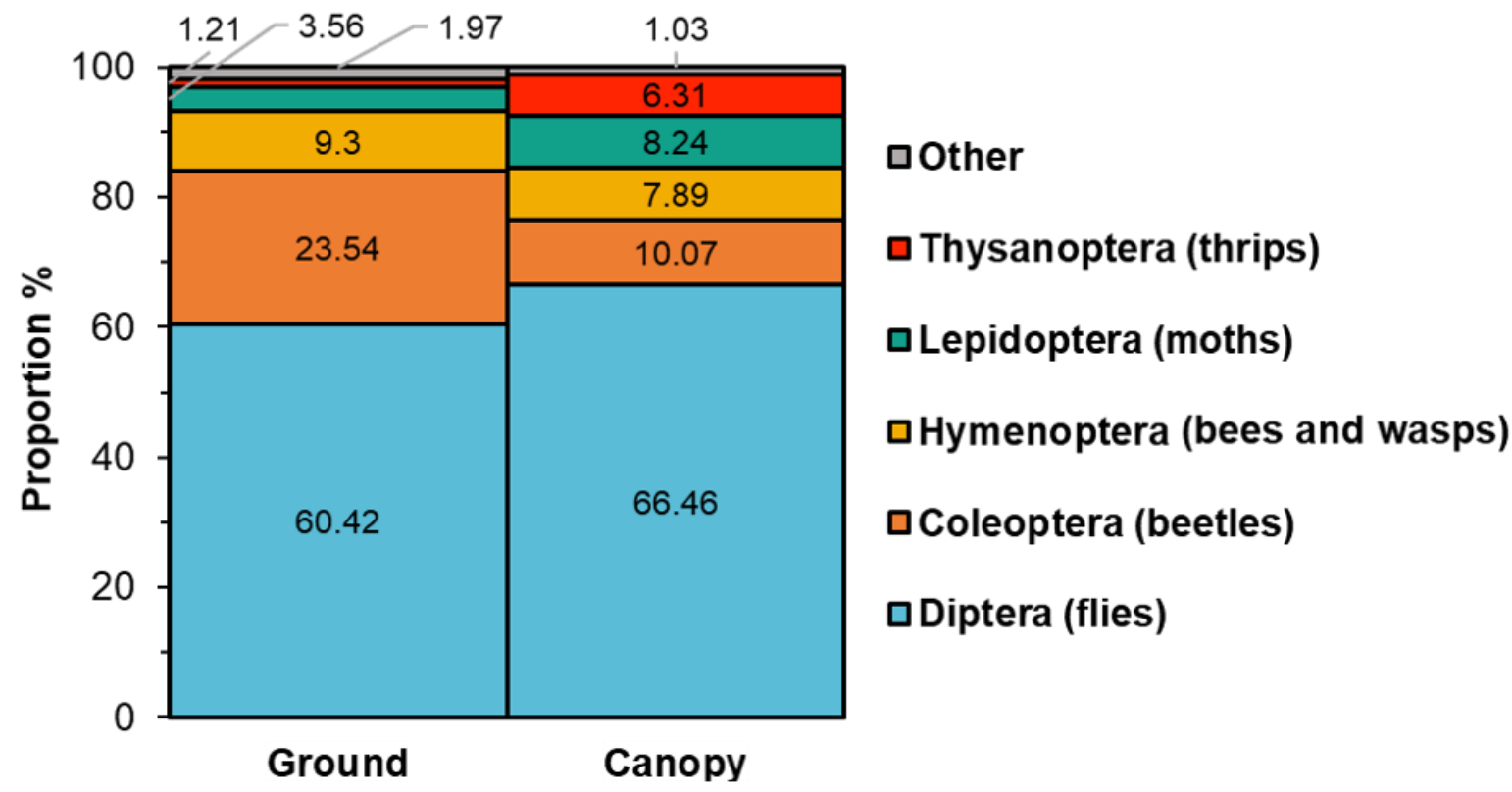

Figure 1. Mosaic chart showing the proportion of insect orders captured in the ground and canopy traps. The total trap captures across all trapping periods on the ground were 3,878 (563 per day) and 5,655 (822 per day) in the canopy. 
(a)

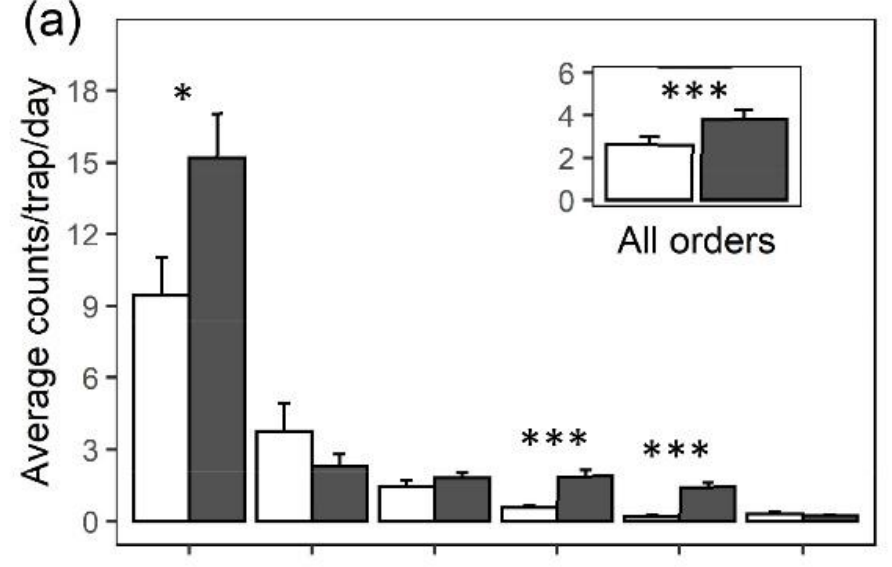

(b)

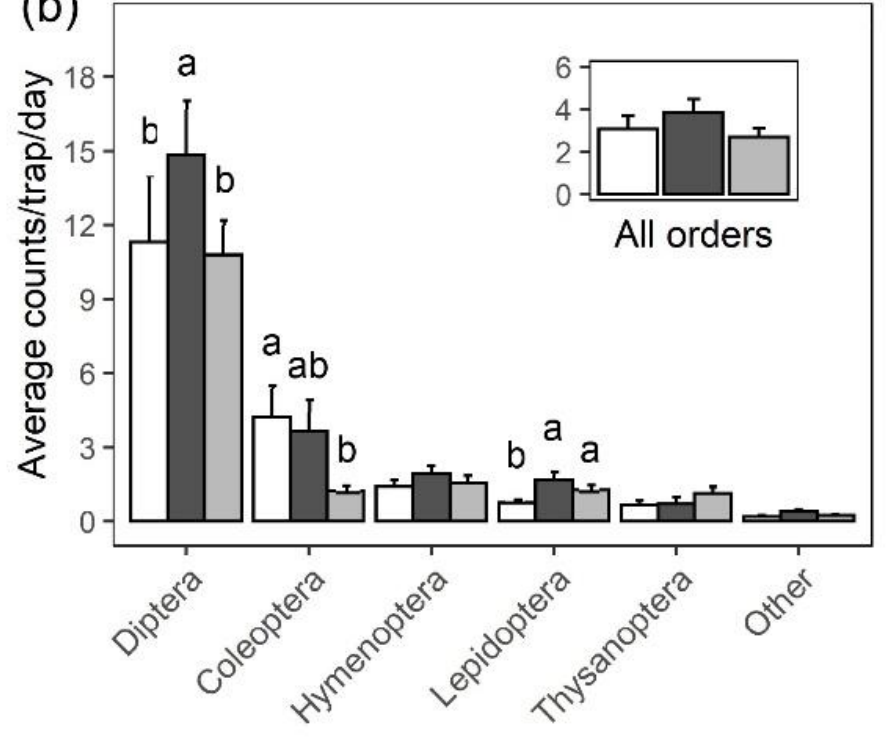

Position

$\begin{array}{r}\square \text { Ground } \\ \hline \text { Canopy }\end{array}$

Period

\begin{tabular}{|l}
$\square$ \\
$\square$ Before \\
\hline$\square$ During \\
After
\end{tabular}

Figure 2. Captures of insects by orders in two trap locations (ground and canopy) and three trapping periods (before, during, and after flowering). Main effect of trap position (a) in doubly repeated measures ANOVA is indicated $\left(\alpha=0.05\right.$ * $^{*}, p<0.05 ; * *, p<0.01$; ***, $\left.p<0.001\right)$ and different letters in each insect order (b) indicate a significant difference in trap captures among flowering periods based on Tukey-Kramer test at $\alpha=0.05$. 

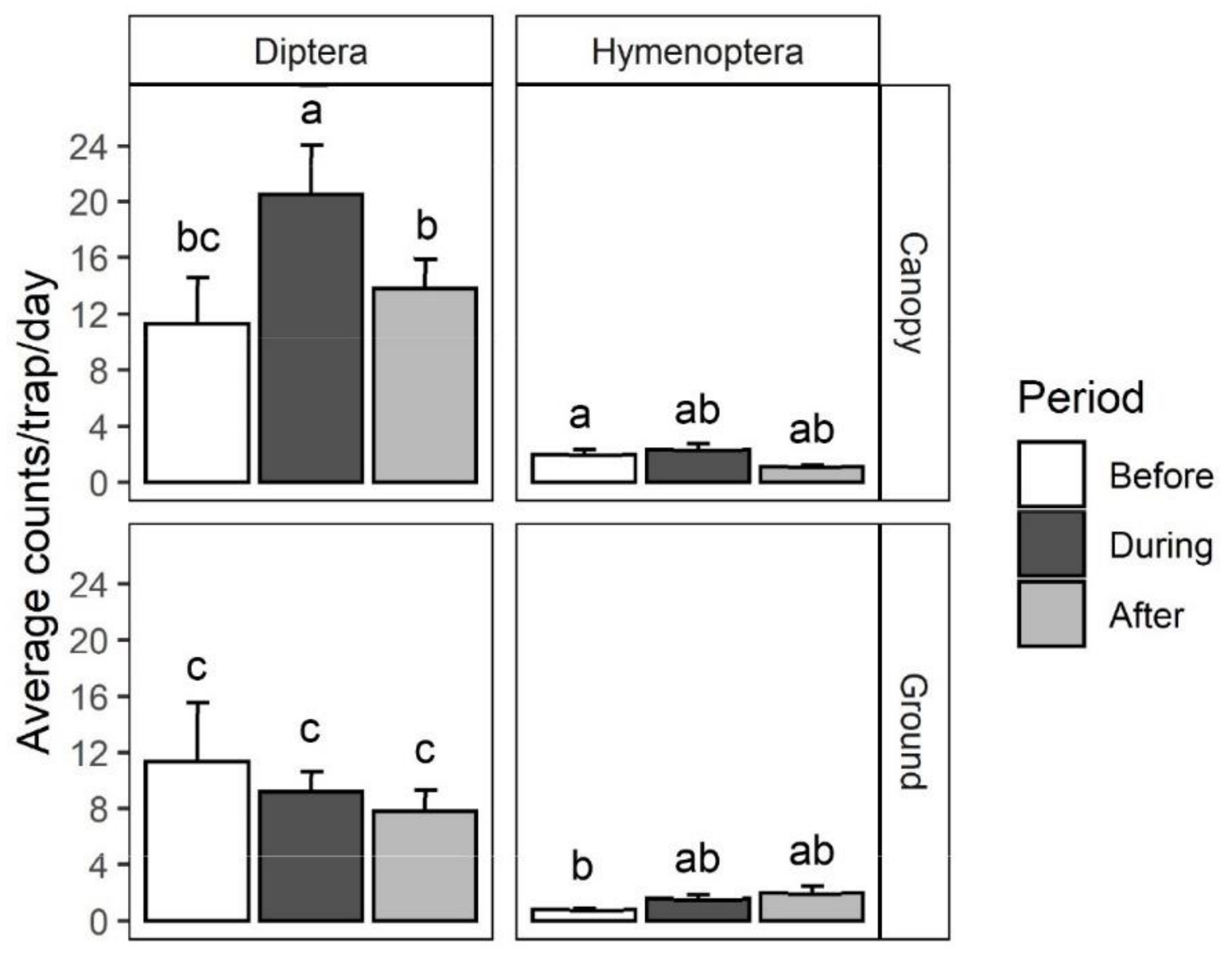

Figure 3. A total of 9,533 insects captured in the traps, and Diptera was the most abundant (64.1\%). Significantly more insects in Diptera, Lepidoptera, and Thysanoptera were captured in the traps installed in the canopy than those on the ground, and Anthalia bulbosa (Diptera: Hybotidae) was the dominant species visiting the canopy of black cherry. 

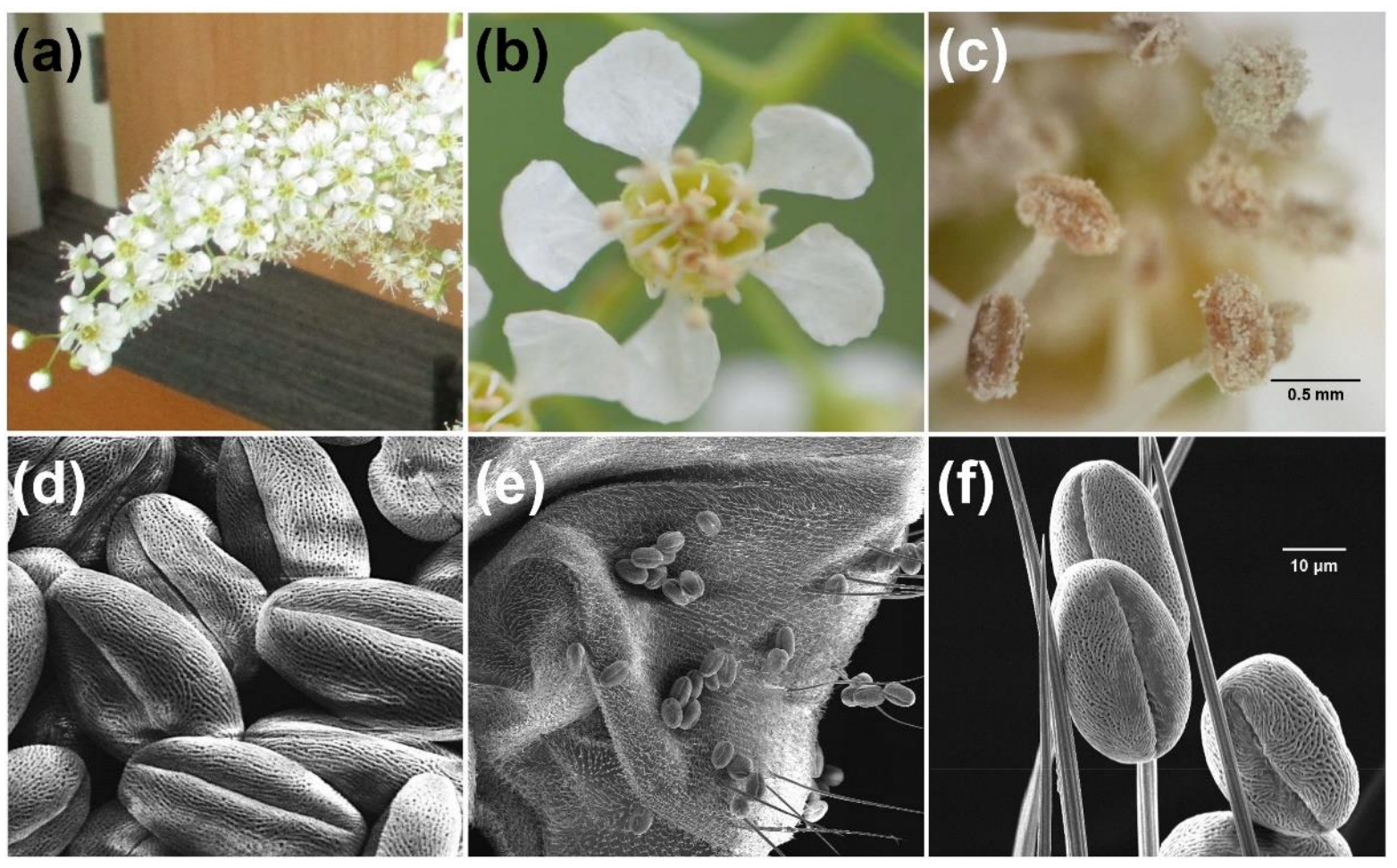

Figure 4. Flowers and pollen grains of black cherry: (a) black cherry raceme in full bloom; (b) a black cherry flower with 5 white petals and 14-15 stamens surrounding a single pistil; (c) anthers after dehiscence; (d) SEM image of pollen grains on anther; (e) SEM image of black cherry pollen grains found on the thorax of Tipula sp. (Diptera: Tipulidae); (f) black cherry pollen grains captured in insect hairs showing the unique exine sculpturing. 

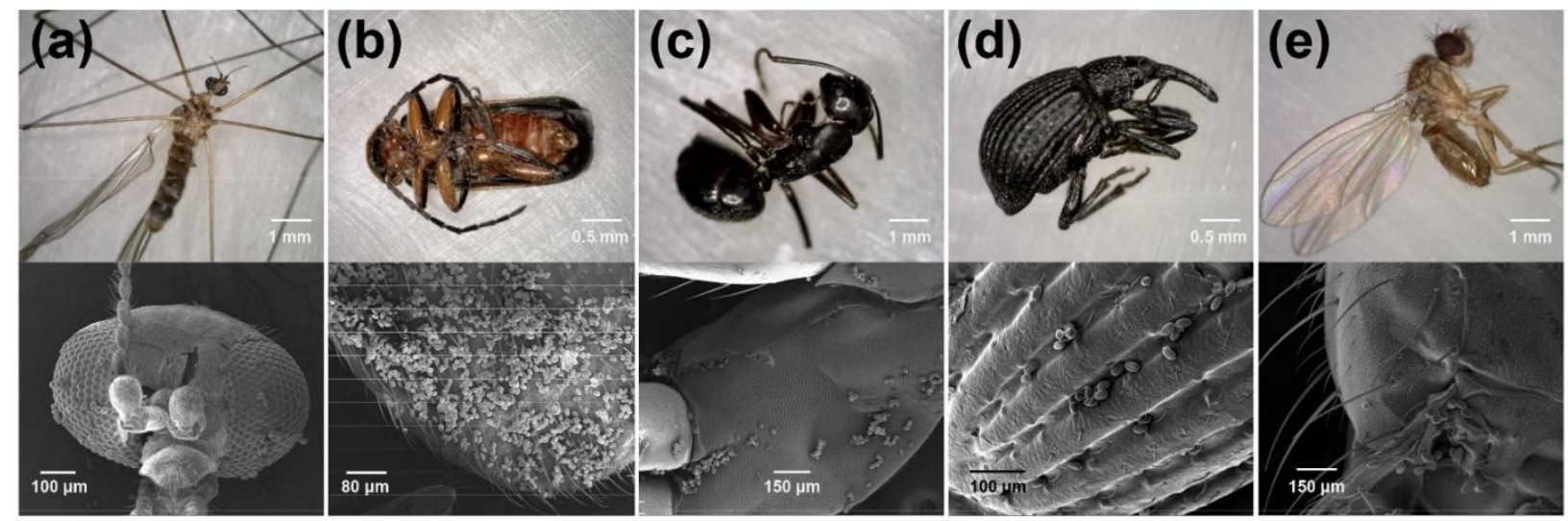

Figure 5. Black cherry pollen grains found on insect body: (a) Antocha sp. (Diptera:

Limoniidae); (b) Atalantycha bilineata (Coleoptera: Cantharidae); (c) Camponotus

pennsylvanicus (Hymenoptera: Formicidae); (d) Trichopion sp. (Coleoptera: Curculionidae); and

(e) Drosophilinae (Diptera: Drosophilidae). 


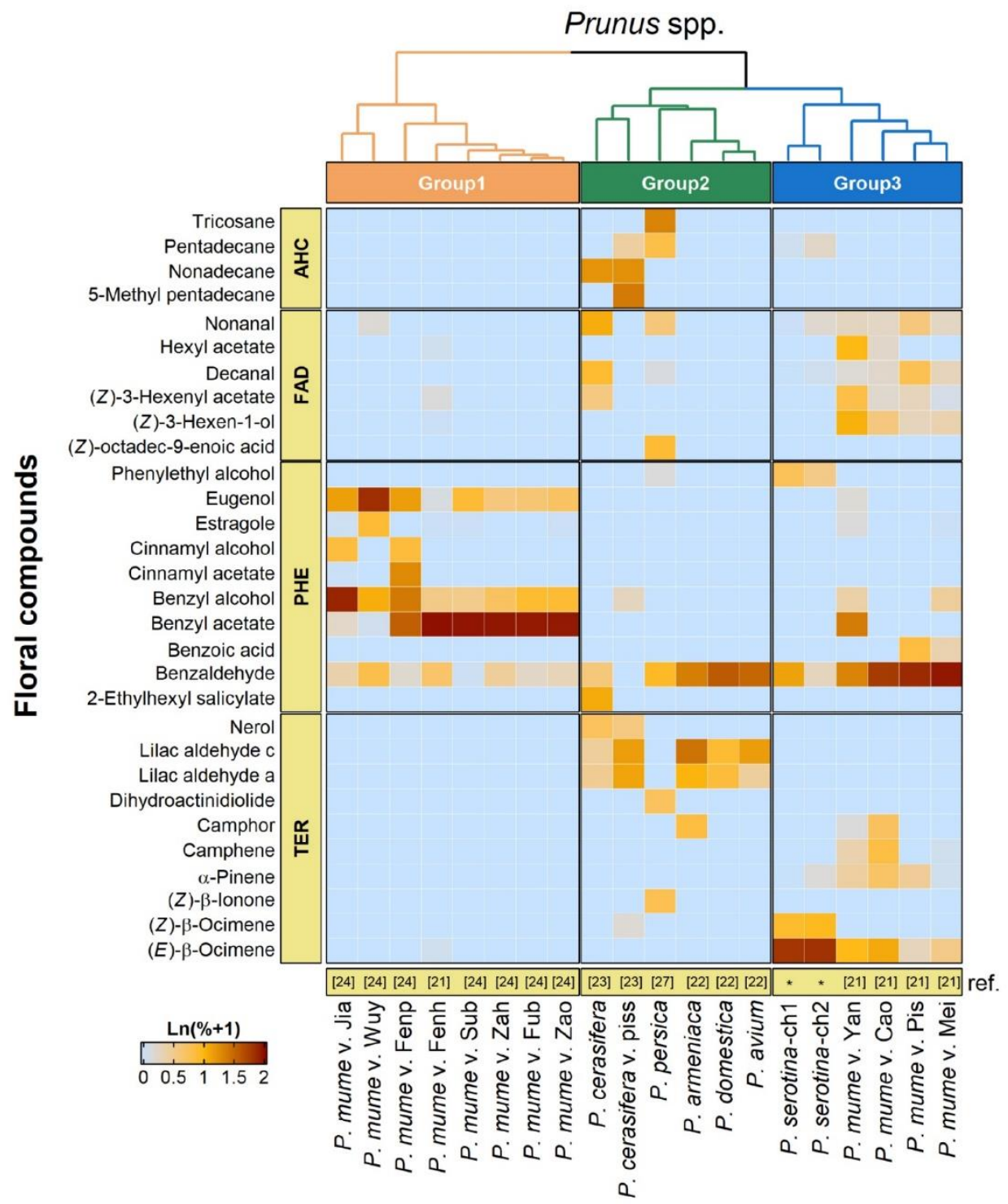

Figure 6. Heatmap and hierarchical clusters (groups 1-3) based on profiles of major floral volatile compounds in Prunus serotina and other Prunus species. Relative abundances (\%) of volatile compounds were normalized by a shifted-log transformation. Prunus species and cultivars were hierarchically clustered by Ward's minimum variance method on Euclidean distances. Classes of floral volatile compounds: TER, terpenes and derivatives; PHE, phenylpropanoids/benzenoids; FAD, fatty acid derivatives; AHC, alkane, and alkene hydrocarbons. * data reported in this study. 


\title{
CHAPTER 3: EFFECTS OF FOREST STAND TYPE ON THE INSECT ASSEMBLAGES OF BLACK CHERRY (PRUNUS SEROTINA) IN THE ALLEGHENY NATIONAL FOREST
}

\begin{abstract}
Over the last decade the Allegheny National Forest (ANF) has experienced issues with the regeneration of black cherry, one of its more valuable timber species. Management of this species is necessary to produce quality timber. Management of the forest changes the structure and function of the habitat for insect species. In this study we investigate how three different silvicultural treatments impact the abundance, diversity, and richness of insect communities in the ANF. These practices are known as the shelterwood seed tree, shelterwood removal methods. Using blue, yellow, and white pan traps we sampled insects at the base and in the canopies of mature black cherry trees. In two locations on the ANF we chose an unmanaged upland hardwood forest stand, a shelterwood seed tree, and shelterwood removal stand. We found differences in Diptera (d.f. $=2, f=7.74, p=0.0010$ ) and Lepidoptera (d.f. $=2, f=3.49, p=$ 0.0423) for the man effect of stand type. Anthalia bulbosa (Diptera, Hybotidae) was found in the canopies in high abundance in all three stand conditions. The species richness and diversity were higher on the ground in all the stand types $($ d.f. $=1, f=11.25, p=0.0014)$, but lower overall counts were observed on the ground (canopy $n=10,409$, ground $n=6,966$ ). This study found low diversity but a high abundance of flower-associated insect species in the canopies of black cherry. Findings in this study could help better understand what the cause of the natural regeneration issue is in the ANF and assist land managers in managing black cherry.
\end{abstract} Keywords: Black cherry, shelterwood, silviculture, pollinators, pan-traps, insect diversity 
The practice of managing forests has been used throughout history worldwide for economic and ecological purposes (Mustian 1975). Black cherry (Prunus serotina Ehrh.) is an important tree species that is managed for its ecological and economic value in the northeastern United States (Maynard et al. 1991). The lumber is highly esteemed by woodworkers and carpenters and the fruit is consumed by a wide diversity of wildlife (Marquis 1990). Black cherry can be found throughout the east coast of the United States and can grow in a variety of different climatic conditions. However, the highest quality black cherry timber originates from the Allegheny Plateau region where the environment is cool, moist, and temperate (Marquis 1990). In particular, the Allegheny National Forest (ANF), in northwestern Pennsylvania, produces some of the highest-quality black cherry in the world. Over the last few decades, the land managers in the ANF have noticed a decline in natural regeneration. The cause of this decline is still unknown, though one hypothesis is a lack of adequate pollination of the flowers.

The management of timber species like black cherry requires the manipulation of a forest ecosystem using heavy machinery, which can have impacts on plant and animal communities including pollinators. Impacts also include soil erosion and compaction, and loss of tree habitat which can have a lasting negative impact on lepidopteran species (Brais and Camile 1998, Savilaakso et al. 2009). The research conducted by Jackson et al. (2014) and Hanula et al. (2015) suggests there is a positive response to open canopies or recently removed clear cuts by some solitary bee communities. However, when the dense herbaceous understory took over, the bee community richness and abundance were noticeably lowered (Hanula 2015). Therefore, the act of silvicultural management could affect insect abundance and diversity.

Foresters in the ANF utilize the even-aged regeneration method to manage shadeintolerant species like black cherry. The two main silvicultural prescriptions used are the 
shelterwood seed tree cut and shelterwood removal cut with reserves (USDA Forest Service 2007). The shelterwood seed-tree method is utilized on mature stands where natural regeneration is desirable and there is an opportunity on the landscape to increase management objectives (USDA Forest Service 2007). This method involves harvesting approximately one-third of the overstory trees, leaving a few well-distributed trees that will provide seed for the next generation. This provides more light to reach the understory and promotes seedling establishment and growth. In contrast, the shelterwood removal cut treatment is conducted approximately 3-15 years after the shelterwood seed tree cut (USDA Forest Service 2007). The stand is at full maturity and ready to have all merchantable tree species harvested, leaving only the unmerchantable wildlife reserve trees (USDA Forest Service 2007). This is the final stand treatment and is visually comparable to a clear cut, reducing tree diversity and canopy closure allowing the highest amount of sunlight to reach the understory. Any of the established seedlings will receive more resources like water, soil nutrients and sunlight. (Figure 1. A-C). This evenaged method is considered the best for the regeneration of Allegheny hardwoods (Hannah 1988). Therefore, if there are no black cherry advanced regeneration (seedlings or saplings) growing in the removal stands at the time of harvest the potential for black cherry failure is possible, as the opening created can allow a new cohort of herbaceous species to thrive. Conceivably a lack of viable seed produced by the parent trees in the shelterwood seed tree cut could be the cause.

Black cherry is a self-incompatible species, which means the flowers require pollinators to transfer pollen from one tree to another to produce viable seeds (Forbes 1969). Little is known about black cherry pollinators in forest stands. A survey conducted by Robertson (1894), in Macoupin County, Illinois, found hymenopterans and dipterans to be the most prevalent species visiting flowers. However, this survey was not conducted on mature black cherry trees in the 
forest. In chapter two, we found that dipterans were the most abundant species to visit black cherry canopies in the forest. There were also higher trap captures during flowering in the canopy, suggesting that the flowers are attracting them to the area. To assist land managers trying to sustain or increase black cherry a further understanding of how silvicultural systems effects pollinator populations is needed. In addition, we found that the flower volatiles profile was similar to those of other pollinator-dependent Prunus species (Larcenaire et al. 2021). This suggests that dipterans are likely attracted to the canopy of the tree when the flowers are present and potentially contribute to pollination. In this chapter we identified whether forest management practices would significantly affect insect communities and diversity in black cherry canopies.

In this study we have postulated that if there are abundant insects in the canopies of different stand types then something other than a deficient of pollinators is likely responsible for the regeneration issues being observed. We explored four main research questions: (1) which stand types support the most insects and what orders are most abundant? (2) will the ground or canopy traps collect more insects?; (3) is there an interaction between the trapping position and stand type when comparing each order?; (4) which stand type and trap positions have the greatest insect species diversity and richness?

\section{Materials and Methods}

Study sites and design. This study was conducted in two separate sites in northwestern Pennsylvania on the Bradford Ranger District on the ANF. The first site was in Cherry Grove $\left(41^{\circ} 43^{\prime} 15.4^{\prime \prime} \mathrm{N} 79^{\circ} 07^{\prime} 16.7^{\prime \prime} \mathrm{W}\right)$ and the other site was near the city of Bradford $\left(41^{\circ} 44^{\prime} 04.2^{\prime \prime} \mathrm{N}\right.$ $78^{\circ} 41^{\prime} 59.1 \mathrm{\prime W}$ ). These sites are in two counties, (Warren and McKean) and are approximately 35 $\mathrm{km}$ apart. Within each of these two sites, three different stand types were selected based on 
silvicultural stand treatment methods employed by the land managers. Within each stand treatment we chose three mature, overstory black cherry trees using a random point generator in ArcGIS (ESRI, Redland, CA). The random points map was uploaded to a Juno ${ }^{\circledR}$ GPS unit (Trimble Inc., Sunnyvale, CA), and a random number generator dictated which point was chosen. The closest black cherry tree to the point on the map was chosen. Each tree had a trap deployed at the base of the tree and in the canopy, approximately halfway into the crown amongst the flowers. The stand types were classified as control, shelterwood seed-tree and shelterwood removal and each stand was approximately $1 \mathrm{~km}$ apart. The shelterwood seed-tree sites were referred to as "shelterwood" in this paper, and the shelterwood removal sites were referred to as "removal". Shelterwood and removal treatment sites were provided by foresters on the ANF, so the stand age and history are known. The shelterwood seed tree and removal cut treatments for the Bradford site were conducted in 2015 and 2017 respectively. Both treatments were conducted for the Cherry Grove site in 2015. The control sites do not have a recent history of treatments and are mixed-age upland hardwood stands.

The control site was an uneven-aged mixed-species stand consisting of the typical upland hardwood species such as eastern hemlock (Tsuga Canadensis), American beech (Fagus grandifolia), tulip poplar (Liriodendron tulipifera), maple (Acer spp.), birch (Betula spp.) and black cherry (Prunus serotina). The selected stand was approximately 30 acres in size and adjacent to forest service roads. The study area was delineated using satellite imagery and Arc GIS software to draw boundaries (Fig. 1). Surveys of the understory herbaceous vegetation during the peak flowering of black cherry were conducted for each of the stand treatments. In each of the stand the plant species were recorded while walking around each of the subject trees. 
Insect Sampling. To sample insects visiting black cherry, we deployed three pairs of colored pan traps in each of the three stand treatments. The traps were deployed for seven days during the peak flowering of black cherry. The study was repeated in the same trees for the years 2018 and 2019. These traps were made using 12-oz plastic cups (12 oz plastic cups, Solo, Lake Forest, IL) colored white, fluorescent yellow and fluorescent blue (Fig. 2A). The yellow and blue cups were painted with fluorescent pigmented paint (Fluorescent Blue and Yellow dispersion, Guerra Paint and Pigment Corp, New York, NY) mixed with a water-based matte flexible acrylic polymer emulsion (Silica Flat, Guerra Paint and Pigment Corp., New York, NY). A solution of $\sim 25$-ml unscented dish soap (Free and Clear dish soap, Seventh Generation, Burlington, VT) per one gallon of water was used to fill the cups. This solution is used to break the surface tension to trap the insects that land in the cup. These colors and trap design have been demonstrated to attract different orders of insects (Droege 2006, Nuttman et al. 2011). The cups were affixed to a platform made from five-gallon bucket lids with three 3-inch holes. A 3pronged metal hanger with two eye loops was attached to the platform for added rigidity and tie points. The canopy traps were hung in the selected tree crown using a slingshot (Big Shot Slingshot, Sherrill Tree, Greensboro, NC) and paracord rope (Fig. 2B). The traps were hung approximately halfway into the canopy near the flowers approximately 60 to 80 feet above the ground. The ground traps were placed below the canopy traps on a twelve-inch wooden stake is attached to a 5-gallon bucket lid. The traps were hung in the canopy for seven days during the peak flowering of the cherry trees. Our goal with this method is to distinguish which insects are attracted to the canopy during the flowering period.

The samples were strained using a fine mesh paint strainer (Mesh Paint Strainer, Harbor Freight Tools, Camarillo, CA) and stored in a sample bag (Whirl Pak, Nasco, Atlanta, GA) with 
$70 \%$ ethyl alcohol. The sample bag was labeled with the trap number, date and trap color. The samples were sorted to order and stored in vials with $70 \%$ ethanol. The orders were then sorted again using parataxonomic sorting methods to morphospecies (Krell 2004). Each morphospecies was given a six-character alphanumeric identification number indicating the insect order and sequential number (e.g., DIP001 and DIP002) and photographed using an Olympus SZ71 microscope and DP21 camera with Cell Sens Dimension software (Olympus DP21, Cell Sens Dimension, Olympus Inc., Tokyo, Japan).

Statistical analysis. The trap captures at the taxonomic level of the order were normalized by dividing by the number of days the traps were deployed in the stands. All three trap colors were combined and treated as one trapping unit. Relationships of stand type, trap position and orders were examined using Pearson's Chi-square frequency analysis. The distribution of all continuous response variables was checked for normality using the ShapiroWilk W Test (Shapiro and Wilk 1965). To correct the lack of normal distribution, a transformation using the square root was performed on the normalized counts +0.0001 . To analyze the abundance of each order (i.e., Coleoptera, Diptera, Lepidoptera, Hymenoptera, Thysanoptera and "Others") as well as on all orders combined, a repeated measures ANOVA in a factorial design was used, testing the main effects of stand type, trap position and their interaction. Repeated factors were the two years with the individual tree as a subject. The insect order was used as a random effect in the model across all combined insect orders. Least square (LS) means of both response variables for the interaction of stand type and trap position were utilized in two sets of slice comparisons. One set compared the trap position effect at each stand type; the second set of slices compared stand types within each trap position using Tukey 
adjustment to multiple comparisons. The relationship of stand type with frequencies of genus/species in each order (i.e., Coleoptera, Diptera, Lepidoptera, Hymenoptera and Thysanoptera), stratified by trap position and year were analyzed using the Cochran-Mantel Haenszel test. While different transformations were applied for analyses, the figures represent untransformed data.

In addition, we used the Simpsons index and species richness formulas to calculate overall species diversity and richness (Simpson 1949) in each stand type and trap position using the morphospecies identification. The species diversity and richness at morphospecies level were also calculated for Coleoptera, Diptera, Lepidoptera and Hymenoptera individually. Because Thysanoptera only has two distinct morphospecies we only included them in the overall diversity and richness calculation and did not analyze them individually. Simpson's Index data lacked normality and were Ln-transformed. Richness data for all orders combined were mostly normally distributed but overdispersion was detected, which was corrected by applying negative binomial distribution in the model. A generalized linear mixed model (Proc GLIMMIX) with negative binomial distribution and Log link was used for species richness, and Gaussian distribution for Ln-transformed Simpson's Index. A similar model structure was used for species richness within individual orders using Ln-transformation, when needed. Least square (LS) means of both response variables generated for the interaction of stand type and trap position were utilized in two sets of slice comparisons. One set compared the trap position effect at each stand type; the second set of slices compared stand types within each trap position using Tukey adjustment to multiple comparisons. 
All statistical analyses were performed in JMP and SAS software (JMP®, Version Pro 16.0, SAS Institute Inc., Cary, NC; SAS®, Version 9.4, SAS Institute Inc., Cary, NC) at $\alpha=$ 0.05 .

\section{Results}

Over the two-year trapping period a total of 17,375 insects were collected in this study. The shelterwood had the highest number of insects overall with $\sim 50 \%$ of the total trap captures $(\mathrm{n}=8,712)$. The removal and control comprised $27 \%(\mathrm{n}=4,771)$ and $22 \%(\mathrm{n}=3,892)$ respectively. With all treatments combined the most abundant orders were Diptera (true flies, 74 $\%, \mathrm{n}=12,668$ ), Coleoptera (beetles, $10 \%, \mathrm{n}=1,780$ ), Hymenoptera (bees and wasps, $8 \%$, $\mathrm{n}=1,477$ ), Lepidoptera (moths and butterflies, 4\%, $n=669$ ), Thysanoptera (thrips, 4\%, $n=612$ ). All other insect orders only comprised $<1 \%$ of the total insects captured (Collembola, Mecoptera, Orthoptera, Plecoptera, Psocoptera, $n=168$ ) (Table 1). The main effect of trap positions was also analyzed with all the stand types and insect orders combined. We found that $60 \%(n=10,409)$ of the trap captures were in the canopy and $40 \%(n=6,966)$ were found in the ground traps (Table 1). We found no statistical main effect of stand type (d.f. $=2, \mathrm{f}=2.86, \mathrm{p}=$ 0.62) or trap position (d.f. $=1, f=3.24, p=0.073$ ) when all insect orders were combined.

Abundance of insects in the stand types. We examined each order for differences across the stand treatments and the orders that showed a significant main effect of stand type were Diptera (d.f. $=2, \mathrm{f}=7.74, \mathrm{p}=0.0010$ ) and Lepidoptera (d.f. $=2, \mathrm{f}=3.49, \mathrm{p}=0.0423$ ). Diptera was more abundant in the shelterwood than compared to the control (d.f. $=66, \mathrm{SEM}=0.3577$, Adj. $\mathrm{p}=0.0018$ ) and the removal (d.f. $=66, \mathrm{SEM}=0.3577$, Adj. $\mathrm{p}=0.006$ ) stands. Lepidoptera had significantly higher captures in the control when compared to the removal stand (d.f. = 33, 
SEM $=0.1286$, Adj. $\mathrm{p}=0.0463)$ but no differences were detected when compared to the shelterwood stands. The removal treatment had the lowest abundance of lepidopterans and the control and shelterwood had similarly high abundances (Fig. 3).

Abundance of insects in different trap positions. For the main effect of trap position, the only two orders showing significance differences were Lepidoptera (d.f. $=1, f=13.25, p=$ 0.0009 ) and Thysanoptera (d.f. $=1, \mathrm{f}=54.14$, Adj. $\mathrm{p}=<0.0001$ ). There is a highly significant difference between the ground and canopy traps for both orders, with a higher abundance found in the canopies (Fig. 4).

Interaction of trap position and stand type in terms of insect abundance. We examined the interaction of the stand types and trapping positions and the only order showing significant interaction was Lepidoptera (d.f. $=2, f=3.65, p=0.0369$ ). The highest captures were from the canopy traps of the control and shelterwood stands (Figure 5). Multiple mean comparisons showed significant differences between the control canopy and the removal canopy (SEM = 0.1603 , d.f. $=61.01, p=0.0292$ ), and with the shelterwood canopy and shelterwood ground $(\mathrm{SEM}=0.1603$, d.f. $=33, \mathrm{p}=0.016)($ Fig. 5). The ground traps across all stand types showed similarities in their low abundance.

Species diversity and richness of insects in different management types. There was a total of 99 morphospecies of Coleoptera, 216 for Diptera, 172 for Hymenoptera, 55 for Lepidoptera, and 2 for Thysanoptera. With all the orders combined we detected a difference in the species diversity for the main effect of trap position (d.f. $=1, f=6.77, p=0.0114$ ) and in the interaction of stand type and trap position (d.f. $=2, f=3.66, p=0.0311)$. The ground traps had a greater species diversity (d.f. $=66, \mathrm{SEM}=0.2796$, Adj. $\mathrm{p}=0.0029$ ) than the canopy. The comparison that 
was caused this interaction was found in the higher diversity in the removal ground traps compared to the removal canopy traps (d.f. $=66, \mathrm{SEM}=0.0827$, Adj $\mathrm{p}=0.0062$ ).

For species richness we found a difference in the interaction of stand type and trap position (d.f. $=2, \mathrm{f}=8.97, \mathrm{p}=0.0004$ ). The comparisons that cause this interaction is the greater species richness in the control canopy traps when compared to the removal canopy traps (d.f. = $66, \mathrm{SEM}=1.6361$, Adj $\mathrm{p}=0.0009)$, and the greater species richness in the shelterwood canopy when compared to the removal canopy (d.f. $=66, \mathrm{SEM}=1.6361$, Adj p =0.0123).

When analyzing the species diversity of each order individually there was a difference in the main effect of stand type (d.f. $=2, f=3.79, p=0.0277$ ) and trap position (d.f. $=1, f=4.8, p$ $=0.0320$ ) for the order Diptera. The ground traps had the highest diversity for trap position and the control had higher diversity than the shelterwood (d.f. $=65, \operatorname{SEM}=0.2450, \operatorname{Adj} \mathrm{p}=0.3612$ ). The removal did not differ in species diversity when compared to the shelterwood (d.f. $=65$, $\mathrm{SEM}=0.1215, \operatorname{Adj} \mathrm{p}=0.3726)$ and control (d.f. $=65, \mathrm{SEM}=0.1235$, Adj $\mathrm{p}=0.3612)$. Of the three stands the control stand had the highest species diversity.

Coleoptera had significant differences in species diversity $($ d.f. $=1, \mathrm{f}=11.25, \mathrm{p}=$ 0.0014), and richness (d.f. $=1, f=17.55, \mathrm{p}=0.0002$ ), for the main effect of trap position. The species diversity and richness were highest in the ground traps. Hymenoptera had significant differences in the species richness for the main effect of trap position (d.f. $=1, \mathrm{f}=6.24, \mathrm{p}=$ 0.0179), and the interaction of stand type and trap position (d.f. $=2, f=4.42, p=0.0203$ ). The highest species richness was found in the ground traps. For the interaction there are differences in the removal canopy and removal ground (d.f. $=30.80, \mathrm{SEM}=0.1611$, Adj. $\mathrm{p}=0.0081$ ), with higher richness in the removal ground. The order Lepidoptera had a difference for the main 
effect of trap position for species richness (d.f. $=1, f=10.08, p=0.0044)$, with the highest diversity found in the canopies (Table 2).

The top ten most abundant species overall were Anthalia bulbosa (Diptera, Hybotidae, 33\%), followed by Smittia spp. (Diptera, Chironomidae, 13\%), Rhamphomyia spp. (Diptera, Empididae, 5\%), Byturus unicolor (Coleoptera, Byturidae, 4\%), Frankliniella occidentalis (Thysanoptera, Thripidae, 4\%), Discocerina spp.,(Diptera, Ephydridae, 4\%), Omalium spp (Coleoptera, Staphylinidae, 2\%), Neuroterus spp. (Hymenoptera, Cynipidae, 2\%), Melanolophia canadaria (Lepidoptera, Geometridae, 2\%), and Rhagio mystaceus (Diptera, Rhagionidae, 2\%). The top ten species captured comprised $69 \%$ of the total trap captures (Table 2). Of these top ten species, seven of them show a strong significance in the canopy traps and five of these species are in the order Diptera. These seven species in the canopy comprise $31 \%$ of the total trap captures (Table 3). We also see the same group of insects are the most abundant in the canopies of each of the stand types (Table 4). For the understory vegetation survey, we found a total of 39 species in the control, 22 species in the shelterwood and 18 species in the removal. (Table 5).

\section{Discussion}

Black cherry is an important species to the Allegheny Plateau region and management of the species is necessary. The goal of this study was to examine if there was a potential deficiency in the insect communities in the canopies of black cherry during flower, which insects are most abundant in the canopies, and whether stand type influences the species diversity and richness of the insect populations. We found no significant effect of stand types on the overall insect abundance. In terms of diversity and richness across stand types we found the highest in the control sites. Therefore, it was necessary to inspect each order for insect order preferences in 
each site and trap position. The data collected reveals that Diptera is the major insect order in all the stand types and trap positions. Many of these dipteran species are known to feed on pollen or are associated with flowers. The trap captures were higher in the shelterwood sites which might suggest that the management implemented to the site is concentrating these species in the canopy of these remaining seed-producing black cherry trees. The resource concentration hypothesis predicts that if there is a resource abundance will support higher loads of plant specific species (Tahvanainen \& Root 1972). Conversely, resource dilution will not support plant specific species and number will be reduced (Otway et al. 2005). The shelterwood stands have higher concentration of resources for black cherry specific flower visitors. This would explain why the dipterans are more abundant where black cherry is in higher concentrations.

The shelterwood site prescription involves removing approximately one-third of the competing overstory and pole tree species in the stand (USDA Forest Service 2007). This lowers the tree diversity in the stand in favor of mature black cherry in the overstory (Table 5). If the dipterans indeed are associated with and using black cherry flowers, it is logical that would be concentrated in the canopy of these remaining shelterwood seed trees. It is also not surprising to find lepidopterans in this stand type because there is still available overstory vegetation for them to utilize. Many lepidopterans are polyphagous and can feed on the vegetation of many different tree and plant species as larvae. Significantly lower numbers of dipterans and lepidopterans found in the removal cut are also an expected result because of the vegetative structure of the stand (Table 5). The removal treatment is designed to drastically lower the trees per acre and tree diversity in a stand through harvesting all merchantable tree species. This condition creates large openings that decrease humidity, increase sunlight to the understory, and raise windspeeds in the 
stand. This also lowers the diversity of the floral resources in the area which is detrimental to flower-visiting insects (Table 4).

A mature black cherry in the ANF can grow to heights of up to $120 \mathrm{feet}$, which is a significant distance for a small insect to travel to find a source of pollen and nectar. Therefore, we believe that most of the insects we found in the canopy during flowering are being attracted to these heights by the flowers. The two orders that showed differences for the main effect of trap position were Lepidoptera and Thysanoptera. In the shelterwood and control stands lepidopterans were more abundant in the canopy. We have found with the interaction of stand type that the lepidopterans prefer a stand with more diverse and abundant overstory vegetation. These insects are likely using the canopy to feed as larvae and as a source of nectar as adults. The moth species that was found the most frequently in the canopy was Melanolophia canadaria. This is a polyphagous species that is known to feed on the leaves of nearly every deciduous tree species found in the control and shelterwood stands as a larva (Butler and Strazanac 2000). The adults have also been recorded to carry black cherry pollen on their bodies which indicates they use black cherry by feeding on nectar and likely contribute to pollination (Lecroy et al. 2013).

The main species of Thysanoptera captured in the canopy was identified as $F$. occidentalis (western flower thrips, WFT). These insects are known as flower dwellers and spend their adult amongst the foliage, fruits and flowers of a wide variety of plant species (Reitz 2009). The larvae will typically drop to the soil when they are ready to pupate but can remain on the plant if the floral structure is complex enough (Reitz 2009). Since the 1970s WFT has spread from its native range of western North America to become a major pest of horticultural and agricultural crops worldwide (Kirk and Terry 2003). It is believed that this species arrived in the 
area through infested plants being transported to greenhouses in Pennsylvania (Kirk and Terry 2003). These are important pests economically due to their feeding habits and ability to transmit viruses (Kirk 1985). We have found from the work in chapter two that some of the VOCs emitted by the flowers of black cherry match VOCs that have been demonstrated to be attractive to WFT (Koschier et al. 2000). Prunus necrotic ringspot virus (PNRSV), and prune dwarf virus (PNV) can be transmitted through pollen found on the bodies of thrips and can cause up to $50 \%$ yield loss in sweet cherry and 100\% yield loss of peach (Greber et al. 1992, Pallas et al. 2012). Although these viruses have not been confirmed in black cherry, they should be investigation in future studies.

The only order to show an interaction of stand type and trap position was Lepidoptera. From our observations we have seen that lepidopterans prefer diverse vegetation and dwell in the canopies of trees. These data show that the captures of lepidopterans depend on which stand type you are trapping in and in what strata you are trapping. If the stand has more diverse overstory vegetation you should expect to find higher numbers of lepidopterans captured in the canopies.

The greatest overall species diversity and richness were found in the ground traps. The understory will typically have more diversity of species than the canopy of a tree. In our vegetation survey we can see a variety of different vegetation for many different insect species to use compared to the one vegetation type in the canopy for insects to utilize. The major species of insects that were captured are known to visit flowers and feed on pollen or nectar (Table 3). These species showed up in each of the sites and had higher numbers in the canopies.

In conclusion we have examined how insect abundance, diversity, and richness would be influenced by different forest stand types. Our findings reflect that the stand treatments did not appear to influence the abundance of insects that were captured. The species richness and 
diversity also seemed to only be affected by the trap position in the removal stands. However, the shelterwood stand did support a greater abundance of insects like dipterans than the other two stand types. Lepidopterans were found to prefer the canopies of the shelterwood and control sites. The dipteran diversity and abundance were found in the stand with the highest abundance of black cherry. Because the main species of lepidopterans we found were known to feed on the nectar of cherry flowers, the lepidopterans appeared to be unaffected by the shelterwood seed tree management as well but were the most susceptible to the removal cut practices. We also found no significant shift in species richness or diversity between stands. Therefore, based on these data we have gathered, it appears that current management activities do not have a significant impact on insect populations and communities. Further studies are needed to investigate if the structural changes in the canopy resulting from management are impacting the movement of insects between trees and creating barriers to cross-pollination. Further studies should also investigate whether the major insects we captured are efficiently cross-pollinating black cherry flowers.

\section{References Cited}

Butler, L., and J. Strazanac. 2000. Occurrence of Lepidoptera on selected host trees in two central Appalachian national forests. Annals of the Entomological Society of America 93: $500-511$.

Brais, S., and C. Camire. 1998. Soil compaction induced by careful logging in the claybelt region of northwestern Quebec (Canada). Canadian Journal of Soil Science 78: 197-206. 
Droege, S. Impact of color and size of bowl trap on numbers of bees captured. 2006. (http://online.sfsu.edu/beeplot/pdfs/color\%20and\%20size.pdf) accessed on 26 January 2021.

Forbes, D.C. 1969. Self-and Cross-Incompatibility in Black Cherry (Prunus serotina), Ph.D. Thesis, University of Florida, Gainesville, FL, USA.

Greber, R. S., Teakle, D. S., \& Mink, G. I. 1992. Thrips-facilitated transmission of prune dwarf and prunus necrotic ringspot viruses from cherry pollen to cucumber. Plant Disease 76: 1039-1041.

Hannah, P. R. 1988. The shelterwood method in northeastern forest types: a literature review. Northern Journal of applied forestry 5: 70-77.

Hanula, J. L., S. Horn, and J. J. O'Brien. 2015. Have changing forests conditions contributed to pollinator decline in the southeastern United States? Forest Ecology and Management 348: 142-152.

Jackson, M. M., M. G. Turner, and S. M. Pearson. 2014. Logging legacies affect insect pollinator communities in southern Appalachian forests. Southeastern Naturalist 13: 317 336.

Kirk, W. D. J. 1985. Pollen-feeding and the host specificity and fecundity of flower thrips (Thysanoptera). Ecological Entomology 10: 281-289.

Kirk, W. D., and L. I. Terry. 2003. The spread of the western flower thrips Frankliniella occidentalis (Pergande). Agricultural and Forest Entomology 5: 301-310.

Klumpers, S. G., 2017. Handling time and flower choice of bees, butterflies and flies foraging on shallow flowers. Beyond random and forbidden interactions in plant-pollinator networks: 
how optimizing energy gain results in morphological matching among subalpine Asteraceae and their flower visitors. Ph.D. dissertation, Leiden University.

Koschier, E. H., W. J. De Kogel, and J. H. Visser. 2000. Assessing the attractiveness of volatile plant compounds to western flower thrips Frankliniella occidentalis. Journal of Chemical Ecology 26: 2643-2655.

Krell, F. T. 2004. Parataxonomy vs. taxonomy in biodiversity studies - pitfalls and applicability of 'morphospecies' sorting. Biodiversity and Conservation 13: 795-812.

Larcenaire, C., F. Wang, I. Holásková, R. Turcotte, M. Gutensohn, and Y.L. Park. 2021. Characterization of the insect assemblage and associated floral volatiles of black cherry (Prunus serotina). Plants 10: 1-18.

LeCroy, K. A., H. W. Shew, and P. A. Van Zandt. 2013. Pollen presence on nocturnal moths in the Ketona Dolomite glades of Bibb County, Alabama. Southern Lepidopterists' News 35: 136-142.

Marquis, D. A. 1990. Prunus serotina Ehrh. black cherry. Silvics of North America 2: 594-604.

Maynard C.A., K. Kavanagh, H. Fuernkranz, A. P. Drew. 1991. Black Cherry (Prunus serotina Ehrh.). In: Bajaj Y.P.S. (eds) Trees III. Biotechnology in Agriculture and Forestry, vol 16. Springer, Berlin, Heidelberg.

Mustian, A. P. 1975. History and philosophy of silviculture management systems in use today. In Proceedings, uneven-aged silviculture and management in the United States, 15-17. July 1975. United States Department of Agriculture.

Nuttman, C. V., Otieno, M., Kwapong, P. K., Combey, R., Willmer, P., \& Potts, S. G. 2011. The utility of aerial pan-trapping for assessing insect pollinators across vertical strata. Journal of the Kansas Entomological Society 84: 260-270. 
Otway, S.J., A. Hector, and J. H. Lawton. 2005. Resource dilution effects on specialist insect herbivores in a grassland biodiversity experiment. Journal of Animal Ecology 74: 234240.

Pallas, V., F. Aparicio, M. C. Herranz, K. Amari, M. A. Sanchez-Pina, A. Myrta, and J. A. Sanchez-Navarro. 2012. Ilarviruses of Prunus spp.: A continued concern for fruit trees. Phytopathology 102: 1108-1120.

Reitz, S. R. 2009. Biology and ecology of the western flower thrips (Thysanoptera: Thripidae): the making of a pest. Florida Entomologist 92: 7-13.

Robertson, C. 1894. Flowers and insects: Rosaceae and Compositae. Academy of Science of St. Louis, Saint Louis, M.O.

Savilaakso, S., J. Koivisto, T. O. Veteli, J. Pusenius, and H. Roininen. 2009. Long lasting impact of forest harvesting on the diversity of herbivorous insects. Biodiversity and Conservation 18: 3931-3948.

Shapiro, S. S., and M. B. Wilk. 1965. An analysis of variance test for normality (complete samples). Biometrika 4: 591-611.

Simpson, E. H. 1949. Measurement of diversity. Nature 163: 688

Tahvanainen, J. O. and R. B. Root. 1972. The influence of vegetational diversity on the population ecology of a specialized herbivore, Phyllotreta cruciferae (Coleoptera: Chrysomelidae. Oecologia 10: 321-346.

U.S. Department of Agriculture, 2007. Allegheny National Forest Record of Decision For Final Environmental Impact Statement and the Land and Resource Management Plan. USDA, Allegheny National Forest. Warren, PA. 
Table 1. Totals and percentages of insect orders captured in each stand type.

\begin{tabular}{|c|c|c|c|c|c|c|c|}
\hline & Diptera & Coleoptera & Hymenoptera & Lepidoptera & Other & Thysanoptera & Total \\
\hline Control Count & 2492 & 615 & 325 & 276 & 66 & 118 & 3892 \\
\hline Total \% & 14.34 & 3.54 & 1.87 & 1.59 & 0.38 & 0.68 & 22.4 \\
\hline $\mathrm{Col} \%$ & 19.67 & 34.55 & 21.99 & 41.19 & 39.52 & 19.28 & \\
\hline Row \% & 64.03 & 15.8 & 8.35 & 7.09 & 1.7 & 3.03 & \\
\hline$\chi^{2}$ & 42.099 & 117.318 & 0.1114 & 105.649 & 21.8537 & 2.6578 & \\
\hline Removal Count & 3438 & 414 & 519 & 69 & 42 & 289 & 4771 \\
\hline Total \% & 19.79 & 2.38 & 2.99 & 0.4 & 0.24 & 1.66 & 27.46 \\
\hline $\mathrm{Col} \%$ & 27.14 & 23.26 & 35.12 & 10.3 & 25.15 & 47.22 & \\
\hline Row \% & 72.06 & 8.68 & 10.88 & 1.45 & 0.88 & 6.06 & \\
\hline$\chi^{2}$ & 0.4717 & 11.438 & 31.5498 & 71.8537 & 0.3243 & 87.0528 & \\
\hline Shelterwood Count & 6738 & 751 & 634 & 325 & 59 & 205 & 8712 \\
\hline Total \% & 38.78 & 4.32 & 3.65 & 1.87 & 0.34 & 1.18 & 50.14 \\
\hline $\mathrm{Col} \%$ & 53.19 & 42.19 & 42.9 & 48.51 & 35.33 & 33.5 & \\
\hline Row \% & 77.34 & 8.62 & 7.28 & 3.73 & 0.68 & 2.35 & \\
\hline$\chi^{2}$ & 23.4737 & 22.4368 & 15.4733 & 0.3566 & 7.3069 & 33.8133 & \\
\hline \multirow{2}{*}{ Total } & 12668 & 1780 & 1478 & 670 & 167 & 612 & \multirow{2}{*}{17375} \\
\hline & 72.91 & 10.24 & 8.51 & 3.86 & 0.96 & 3.52 & \\
\hline
\end{tabular}


Table 2. Simpsons Index of Diversity (D) and species richness (Da) were calculated for each order individually to determine which stand types and trap positions the most diversity and richness occurred.

\begin{tabular}{|c|c|c|c|c|c|c|c|c|c|c|c|c|c|}
\hline Stand Type & Position & $\begin{array}{c}\text { Coleoptera } \\
\text { Species Count }\end{array}$ & $D$ & $D a$ & $\begin{array}{c}\text { Diptera } \\
\text { Species Count }\end{array}$ & $D$ & $D a$ & $\begin{array}{l}\text { Hymenoptera } \\
\text { Species Count }\end{array}$ & $D$ & $D a$ & $\begin{array}{l}\text { Lepidoptera } \\
\text { Species Count }\end{array}$ & $D$ & $D a$ \\
\hline \multirow[t]{3}{*}{ Control Total } & & 50 & 0.82 & 5.39 & 143 & 0.81 & 9.83 & 89 & 0.84 & 5.38 & 46 & 0.64 & 4.11 \\
\hline & Canopy & 42 & 0.81 & 5.43 & 104 & 0.75 & 10.44 & 60 & 0.86 & 5.49 & 38 & 0.58 & 4.05 \\
\hline & Ground & 18 & 0.84 & 5.35 & 95 & 0.86 & 9.22 & 47 & 0.83 & 5.27 & 18 & 0.74 & 4.18 \\
\hline \multicolumn{2}{|l|}{ Removal Total } & 48 & 0.82 & 5.47 & 136 & 0.71 & 9.00 & 98 & 0.79 & 5.45 & 20 & 0.54 & 3.18 \\
\hline & Canopy & 28 & 0.75 & 3.86 & 85 & 0.60 & 7.52 & 47 & 0.70 & 3.96 & 12 & 0.55 & 2.98 \\
\hline & Ground & 25 & 0.87 & 6.94 & 108 & 0.81 & 10.48 & 72 & 0.88 & 6.94 & 12 & 0.54 & 3.36 \\
\hline \multicolumn{2}{|c|}{ Shelterwood Total } & 57 & 0.73 & 5.91 & 147 & 0.63 & 9.17 & 108 & 0.79 & 6.63 & 36 & 0.65 & 3.79 \\
\hline & Canopy & 38 & 0.62 & 4.74 & 111 & 0.61 & 8.94 & 63 & 0.76 & 6.18 & 29 & 0.71 & 4.26 \\
\hline & Ground & 29 & 0.83 & 7.08 & 100 & 0.64 & 9.40 & 77 & 0.83 & 7.08 & 14 & 0.54 & 2.93 \\
\hline
\end{tabular}


Table 3. The top ten most abundant insect species captured in this study

\begin{tabular}{|c|c|c|c|c|c|c|c|c|}
\hline Order & Family & Species & Ground & Canopy & ChiSquare & D.F. & PValue & $\%$ of Total \\
\hline Diptera & Hybotidae & Anthalia bulbosa (Male) & 1839 & 1573 & 238.70 & 1 & $<.0001$ & $20.20 \%$ \\
\hline Diptera & Hybotidae & Anthalia bulbosa (Female) & 38 & 2088 & 105.72 & 1 & $<.0001$ & $12.58 \%$ \\
\hline Diptera & Chironomidae & Smittia spp. & 875 & 1351 & 27.25 & 1 & $<.0001$ & $13.18 \%$ \\
\hline Diptera & Empididae & Rhamphomyia spp. & 497 & 425 & 35.28 & 1 & $<.0001$ & $5.46 \%$ \\
\hline Coleoptera & Byturidae & Byturus unicolor & 540 & 173 & 248.15 & 1 & $<.0001$ & $4.22 \%$ \\
\hline Thysanoptera & Thripidae & Frankliniella spp. & 97 & 496 & 0.49 & 1 & $<.0001$ & $3.51 \%$ \\
\hline Diptera & Ephydridae & Discocerina spp. & 94 & 409 & 98.84 & 1 & $<.0001$ & $2.98 \%$ \\
\hline Coleoptera & Staphylinidae & Omalium spp. & 31 & 310 & 61.68 & 1 & $<.0001$ & $2.02 \%$ \\
\hline Hymenoptera & Cynipidae & Neuroterus spp. & 13 & 293 & 27.87 & 1 & $<.0001$ & $1.81 \%$ \\
\hline Lepidoptera & Geometridae & Melanolophia canadaria & 20 & 278 & 37.76 & 1 & $<.0001$ & $1.76 \%$ \\
\hline Diptera & Rhagionidae & Rhagio mystaceus & 229 & 68 & 74.49 & 1 & $<.0001$ & $1.76 \%$ \\
\hline
\end{tabular}


Table 4. The most abundant insect species found in all of the stand types

\begin{tabular}{|c|c|c|c|c|c|c|c|c|}
\hline \multirow{2}{*}{\begin{tabular}{|l|} 
Order \\
Diptera
\end{tabular}} & Species & \multirow{2}{*}{$\frac{\text { Stand }}{l e}$} & \multicolumn{2}{|c|}{ Canopy } & \multicolumn{2}{|c|}{ Ground } & \multicolumn{2}{|c|}{ Grand Total } \\
\hline & Anthalia bulbosa ma & & 1573 & $13.76 \%$ & 1839 & $16.09 \%$ & 3412 & $29.85 \%$ \\
\hline & & Control & 343 & $3.00 \%$ & 170 & $1.49 \%$ & 513 & $4.49 \%$ \\
\hline & & Removal & 600 & $5.25 \%$ & 746 & $6.53 \%$ & 1346 & $11.78 \%$ \\
\hline & & Shelterwood & 630 & $5.51 \%$ & 923 & $8.08 \%$ & 1553 & $13.59 \%$ \\
\hline \multirow[t]{4}{*}{ Diptera } & \multicolumn{2}{|c|}{ Anthalia bulbosa female } & 2088 & $18.27 \%$ & 38 & $0.33 \%$ & 2126 & $18.60 \%$ \\
\hline & & Control & 307 & $2.69 \%$ & 3 & $0.03 \%$ & 310 & $2.71 \%$ \\
\hline & & Removal & 738 & $6.46 \%$ & 6 & $0.05 \%$ & 744 & $6.51 \%$ \\
\hline & & Shelterwood & 1043 & $9.13 \%$ & 29 & $0.25 \%$ & 1072 & $9.38 \%$ \\
\hline \multirow[t]{4}{*}{ Diptera } & Smittia spp. & & 1351 & $11.82 \%$ & 875 & $7.66 \%$ & 2226 & $19.48 \%$ \\
\hline & & Control & 380 & $3.32 \%$ & 199 & $1.74 \%$ & 579 & $5.07 \%$ \\
\hline & & Removal & 158 & $1.38 \%$ & 76 & $0.66 \%$ & 234 & $2.05 \%$ \\
\hline & & Shelterwood & 813 & $7.11 \%$ & 600 & $5.25 \%$ & 1413 & $12.36 \%$ \\
\hline \multirow[t]{4}{*}{ Diptera } & Rhamphomyia spp. & & 425 & $3.72 \%$ & 497 & $4.35 \%$ & 922 & $8.07 \%$ \\
\hline & & Control & 152 & $1.33 \%$ & 43 & $0.38 \%$ & 195 & $1.71 \%$ \\
\hline & & Removal & 47 & $0.41 \%$ & 147 & $1.29 \%$ & 194 & $1.70 \%$ \\
\hline & & Shelterwood & 226 & $1.98 \%$ & 307 & $2.69 \%$ & 533 & $4.66 \%$ \\
\hline \multirow[t]{4}{*}{ Coleoptera } & Byturus unicolor & & 173 & $1.51 \%$ & 540 & $4.72 \%$ & 713 & $6.24 \%$ \\
\hline & & Control & 44 & $0.38 \%$ & 265 & $2.32 \%$ & 309 & $2.70 \%$ \\
\hline & & Removal & 44 & $0.38 \%$ & 185 & $1.62 \%$ & 229 & $2.00 \%$ \\
\hline & & Shelterwood & 85 & $0.74 \%$ & 90 & $0.79 \%$ & 175 & $1.53 \%$ \\
\hline \multirow[t]{4}{*}{ Thysanoptera } & \multicolumn{2}{|c|}{ Frankliniella occidentalis } & 496 & $4.34 \%$ & 97 & $0.85 \%$ & 593 & $5.19 \%$ \\
\hline & & Control & 99 & $0.87 \%$ & 14 & $0.12 \%$ & 113 & $0.99 \%$ \\
\hline & & Removal & 243 & $2.13 \%$ & 45 & $0.39 \%$ & 288 & $2.52 \%$ \\
\hline & & Shelterwood & 154 & $1.35 \%$ & 38 & $0.33 \%$ & 192 & $1.68 \%$ \\
\hline \multirow[t]{4}{*}{ Diptera } & Discocerina spp. & & 409 & $3.43 \%$ & 94 & $0.79 \%$ & 503 & $4.22 \%$ \\
\hline & & Control & 116 & $0.97 \%$ & 3 & $0.03 \%$ & 119 & $1.00 \%$ \\
\hline & & Removal & 21 & $0.18 \%$ & 39 & $0.33 \%$ & 60 & $0.50 \%$ \\
\hline & & Shelterwood & 272 & $2.28 \%$ & 52 & $0.44 \%$ & 324 & $2.72 \%$ \\
\hline \multirow[t]{4}{*}{ Coleoptera } & Omalium spp. & & 310 & $2.71 \%$ & 31 & $0.27 \%$ & 341 & $2.98 \%$ \\
\hline & & Control & 30 & $0.26 \%$ & 2 & $0.02 \%$ & 32 & $0.28 \%$ \\
\hline & & Removal & 63 & $0.55 \%$ & 5 & $0.04 \%$ & 68 & $0.59 \%$ \\
\hline & & Shelterwood & 217 & $1.90 \%$ & 24 & $0.21 \%$ & 241 & $2.11 \%$ \\
\hline \multirow[t]{4}{*}{ Hymenoptera } & Neuroterus spp. & & 293 & $2.56 \%$ & 13 & $0.11 \%$ & 306 & $2.68 \%$ \\
\hline & & Control & 49 & $0.43 \%$ & 8 & $0.07 \%$ & 57 & $0.50 \%$ \\
\hline & & Removal & 92 & $0.80 \%$ & 4 & $0.03 \%$ & 96 & $0.84 \%$ \\
\hline & & Shelterwood & 152 & $1.33 \%$ & 1 & $0.01 \%$ & 153 & $1.34 \%$ \\
\hline \multirow[t]{4}{*}{ Lepidoptera } & \multicolumn{2}{|c|}{ Melanolophia canadaria } & 278 & $2.43 \%$ & 20 & $0.17 \%$ & 298 & $2.61 \%$ \\
\hline & & Control & 118 & $1.03 \%$ & 13 & $0.11 \%$ & 131 & $1.15 \%$ \\
\hline & & Removal & 10 & $0.09 \%$ & 2 & $0.02 \%$ & 12 & $0.10 \%$ \\
\hline & & Shelterwood & 150 & $1.31 \%$ & 5 & $0.04 \%$ & 155 & $1.36 \%$ \\
\hline \multirow[t]{4}{*}{ Diptera } & Rhagio mystaceus & & 68 & $0.59 \%$ & 229 & $2.00 \%$ & 297 & $2.60 \%$ \\
\hline & & Control & 19 & $0.17 \%$ & 18 & $0.16 \%$ & 37 & $0.32 \%$ \\
\hline & & Removal & 3 & $0.03 \%$ & 77 & $0.67 \%$ & 80 & $0.70 \%$ \\
\hline & & Shelterwood & 46 & $0.40 \%$ & 134 & $1.17 \%$ & 180 & $1.57 \%$ \\
\hline
\end{tabular}


Table 5. The vegetation survey revealed more understory herbaceous species in the control with

39 different plant species. The shelterwood had the second most with 22 and the removal had the

least with 18. A higher understory vegetation abundance helps explain why insect species and

diversity were highest in the ground traps.

\begin{tabular}{|c|c|c|c|c|c|c|}
\hline Common Name & Family & Genus & Species & Contol & $\begin{array}{c}\text { Stand type } \\
\text { Shelterwood }\end{array}$ & Removal \\
\hline Elderberry & Adoxaceae & Sambucus & spp. & $x$ & & \\
\hline Staghorn Sumac & Anacardiaceae & Rhus & typhina & $x$ & & \\
\hline Mountain Holly & Aquifoliaceae & Ilex & montana & & $x$ & \\
\hline Jack-in-the-pulpit & Aracae & Arisaema & triphyllum & $x$ & & \\
\hline Devil's walking stick & Araliaceae & Aralia & spinosa & & $x$ & \\
\hline Dwarf Ginsing & & Panax & trifolius & $x$ & & \\
\hline Canada Mayflower & Asparagaceae & Maianthemum & canadense & $x$ & & $x$ \\
\hline Solomon's seal & & Polygonatum & pubescens & $x$ & & \\
\hline Goldenrod & Asteraceae & Solidago & spp. & & $x$ & \\
\hline Mayapple & Berberidaceae & Podophyllum & peltatum & $x$ & & \\
\hline Black Birch & Betulaceae & Betula & lenta & & $x$ & $x$ \\
\hline Sessile Bellwort & Colchicaceae & Uvularia & sessilifolia & $x$ & & \\
\hline Sedge & Cyperaceae & Carex & debilis & $x$ & $x$ & $x$ \\
\hline Pink Ladies Slipper & Cypripedioideae & Cypripedium & acaule & $x$ & & \\
\hline Hay-scented fern & Dennstaedtiaceae & Dennstaedtia & punctilobula & & & $x$ \\
\hline Intermediate Wood Fern & Dryopteridaceae & Dryopteris & intermedia & $x$ & $x$ & $x$ \\
\hline American Beech & Fagacae & Fagus & grandifolia & $x$ & $x$ & $x$ \\
\hline Indian Cucumber Root & Liliaceae & Medeola & virginiana & $x$ & $x$ & \\
\hline Trout Lily & & Erythronium & americanum & $x$ & & \\
\hline Creeping Ground cedar & Lycopodiaceae & Diphasiastrum & digatatum & $x$ & & $x$ \\
\hline Ground Pine & & Lycopodium & dendroideum & & $x$ & \\
\hline Ground Pine & & Lycopodium & obscurum & $x$ & $x$ & \\
\hline Running Ground Cedar & & Diphasiastrum & digatatum & & & $x$ \\
\hline Shining clubmoss & & Huperzia & lucidula & $x$ & & \\
\hline Cucumber Magnolia & Magnoliacae & Magnolia & acuminata & $x$ & $x$ & $x$ \\
\hline Tulip tree & & Liriodendron & tulipifera & $x$ & $x$ & $x$ \\
\hline Painted Trillium & Melanthiaceae & Trillium & undulatum & $x$ & $x$ & \\
\hline White trillium & & Trillium & grandiflora & $x$ & & \\
\hline Green Ash & Oleaceae & Fraxinus & americana & & $x$ & \\
\hline Beechdrops & Orobanchaceae & Epifagus & virginiana & $x$ & & \\
\hline Cinnamon Fern & Osmundaceae & Osmunda & cinnamomea & $x$ & & \\
\hline Wood Sorrel & Oxalidaceae & Oxalis & montana & $x$ & & \\
\hline Eastern Hemlock & Pinaceae & Tsuga & canadensis & $x$ & & \\
\hline Deer Tongue Grass & Poaceae & Dichanthelium & clandestine & $x$ & & $x$ \\
\hline Short Husk Grass & & Brachyelytrum & erectum & $x$ & & $x$ \\
\hline Starflower & Primulaceae & Trientilla & borealis & $x$ & & \\
\hline Blackberry & Rosaceae & Rubus & allegheniensis & $x$ & & $x$ \\
\hline Bristly Dewberry & & Rubus & hispidus & $x$ & & \\
\hline Pin Cherry & & Prunus & pensylvanica & & $x$ & $x$ \\
\hline Raspberry & & Rubus & idaeus & $x$ & & \\
\hline Serviceberry & & Amelanchier & arborea & $x$ & $x$ & \\
\hline Black Cherry & & Prunus & serotina & $x$ & $x$ & $x$ \\
\hline Chokecherry & & Prunus & virginiana & & $x$ & \\
\hline Partridgeberry & Rubiaceae & Mitella & repens & $x$ & & \\
\hline Red Maple & Sapindaceae & Acer & rubrum & $x$ & $x$ & $x$ \\
\hline Striped Maple & & Acer & pensylvanicum & $x$ & $x$ & \\
\hline New York Fern & Thelypteridaceae & Thelypteris & noveboracensis & $x$ & & $x$ \\
\hline Round leaved violet & Violaceae & Viola & rotundifolia & $x$ & $x$ & \\
\hline Sweet White Violet & & Viola & blanda & $x$ & $x$ & $x$ \\
\hline
\end{tabular}




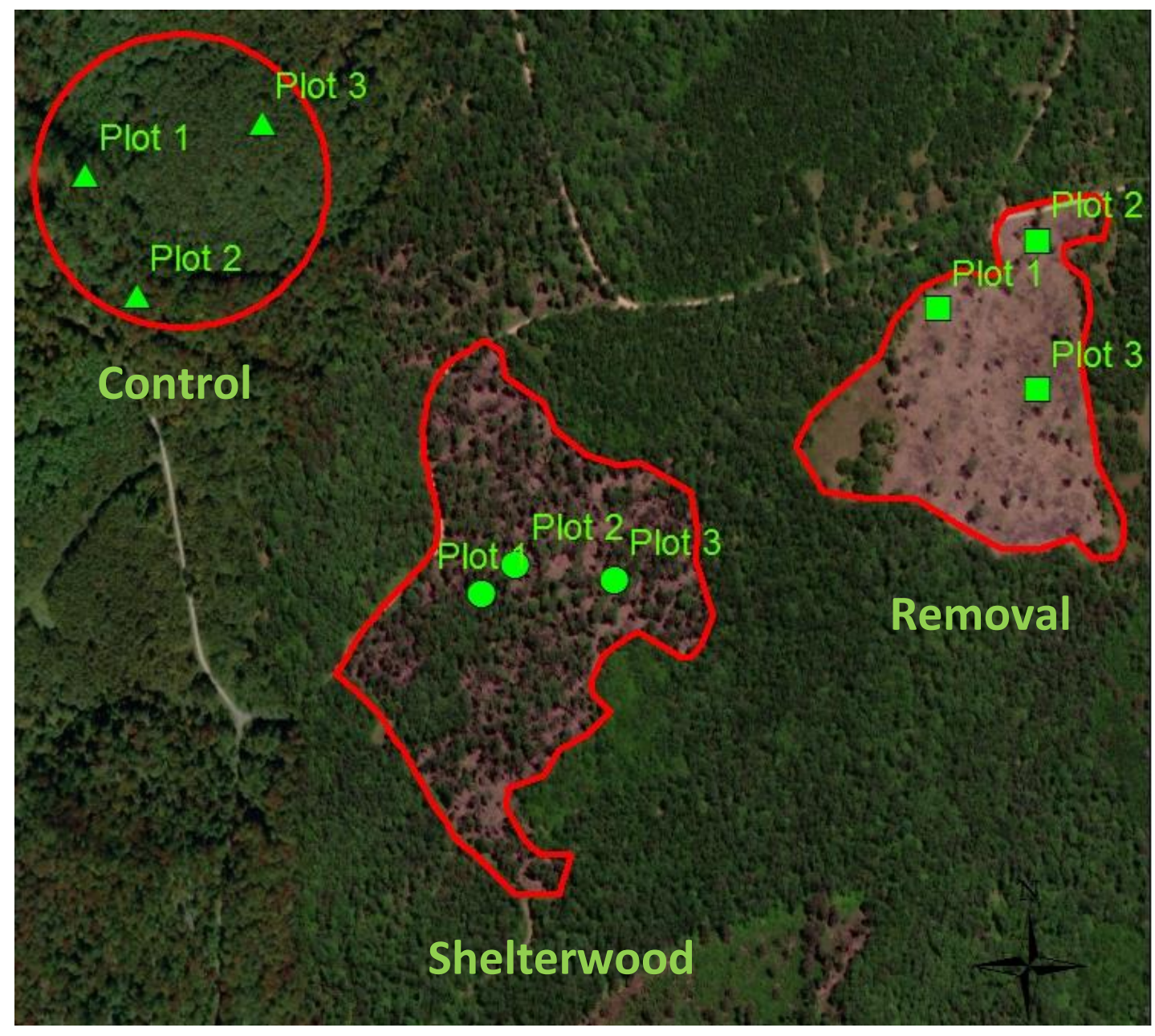

Fig. 1. Satellite image of the three stand types in Bradford. Three mature black cherry trees were chosen at random within these boundaries using random points in Arc GIS and a random number generator. The differences in canopy cover between the three stands are easily seen in this image. 

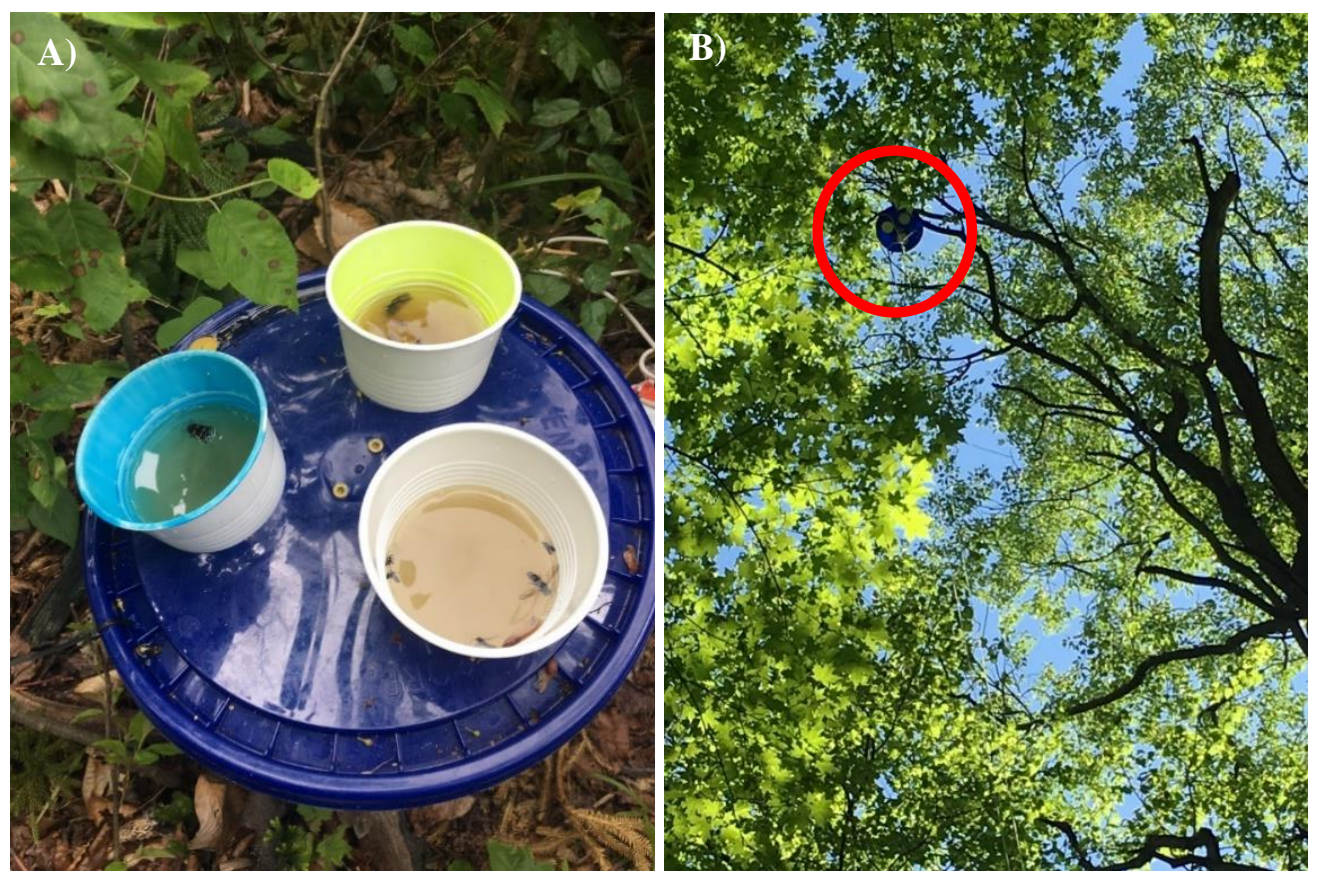

Fig. 2. Pan trap ground array with $12 \mathrm{oz}$ plastic cups with blue and yellow fluorescent paint. This trap was positioned $\sim 12$ inches off the ground (A) and canopy trap array hung in black cherry circled in red (B). These traps were hung halfway up the canopy of the tree $\sim 60-80$ feet from the ground 


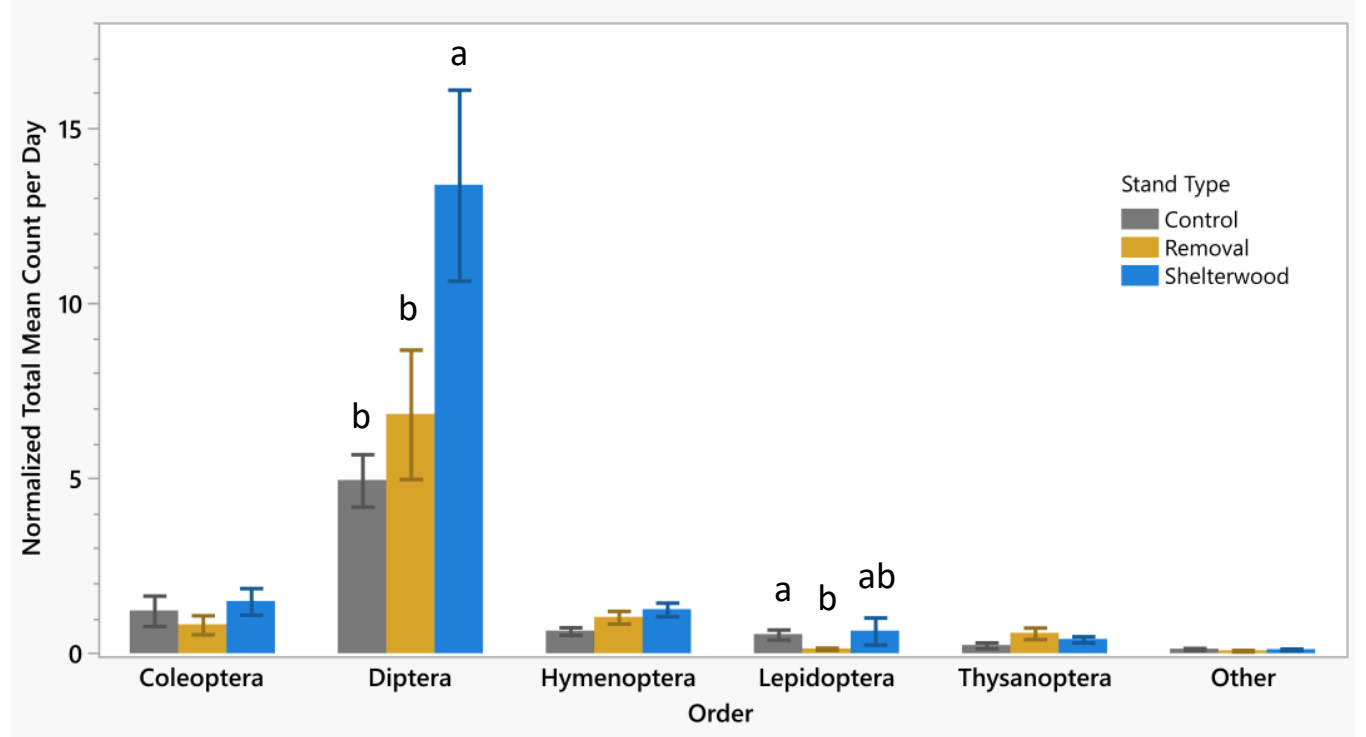

Fig 3. Comparison of insect abundance in each insect order among different stand types. The orders that showed significance at $\alpha=0.05$ was given letters above the bars. Significance was tested within the order and was not tested comparing all interactions. 


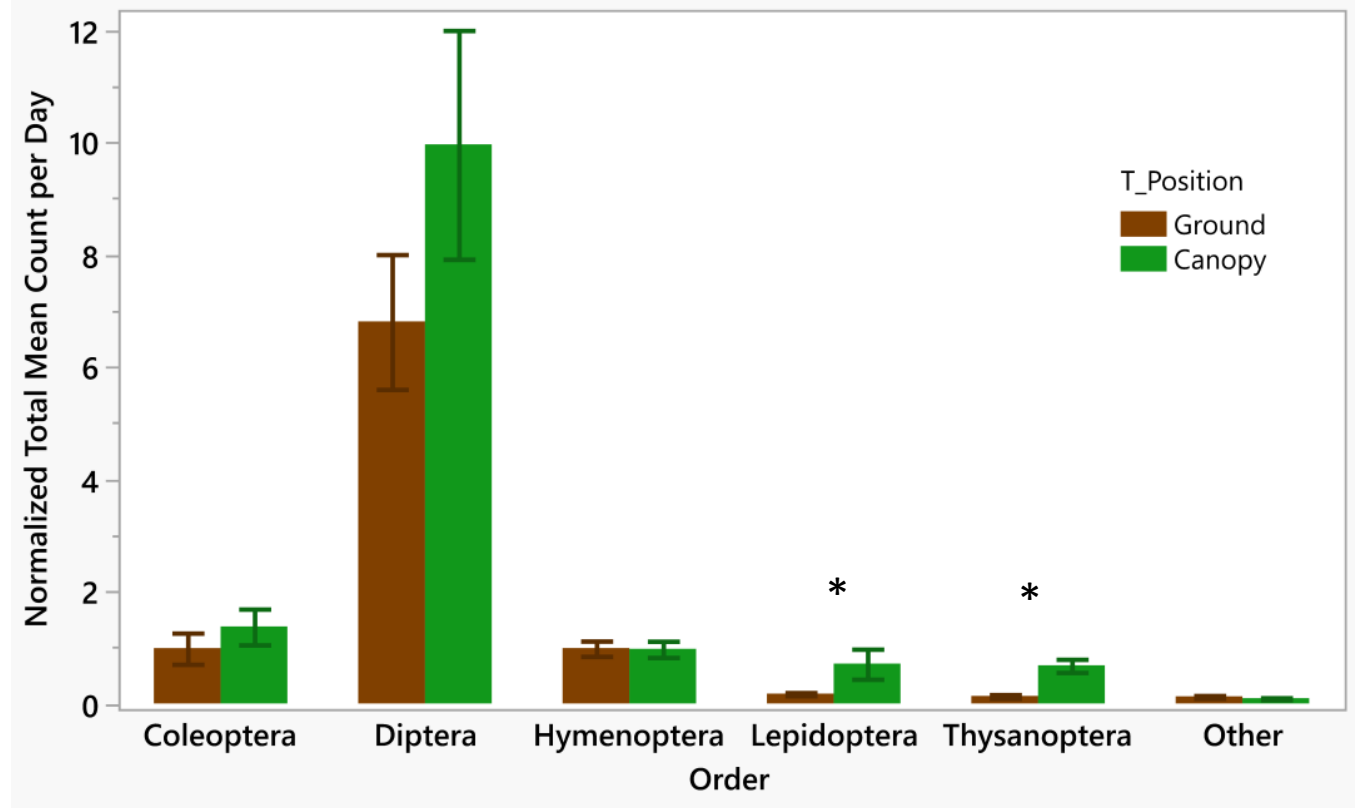

Fig 4. Comparison of insect abundances in each order (all the sites combined) between ground and canopy traps. The asterisk above the bars indicates a significant difference in trap position for the insect order at $\alpha=0.05$. 


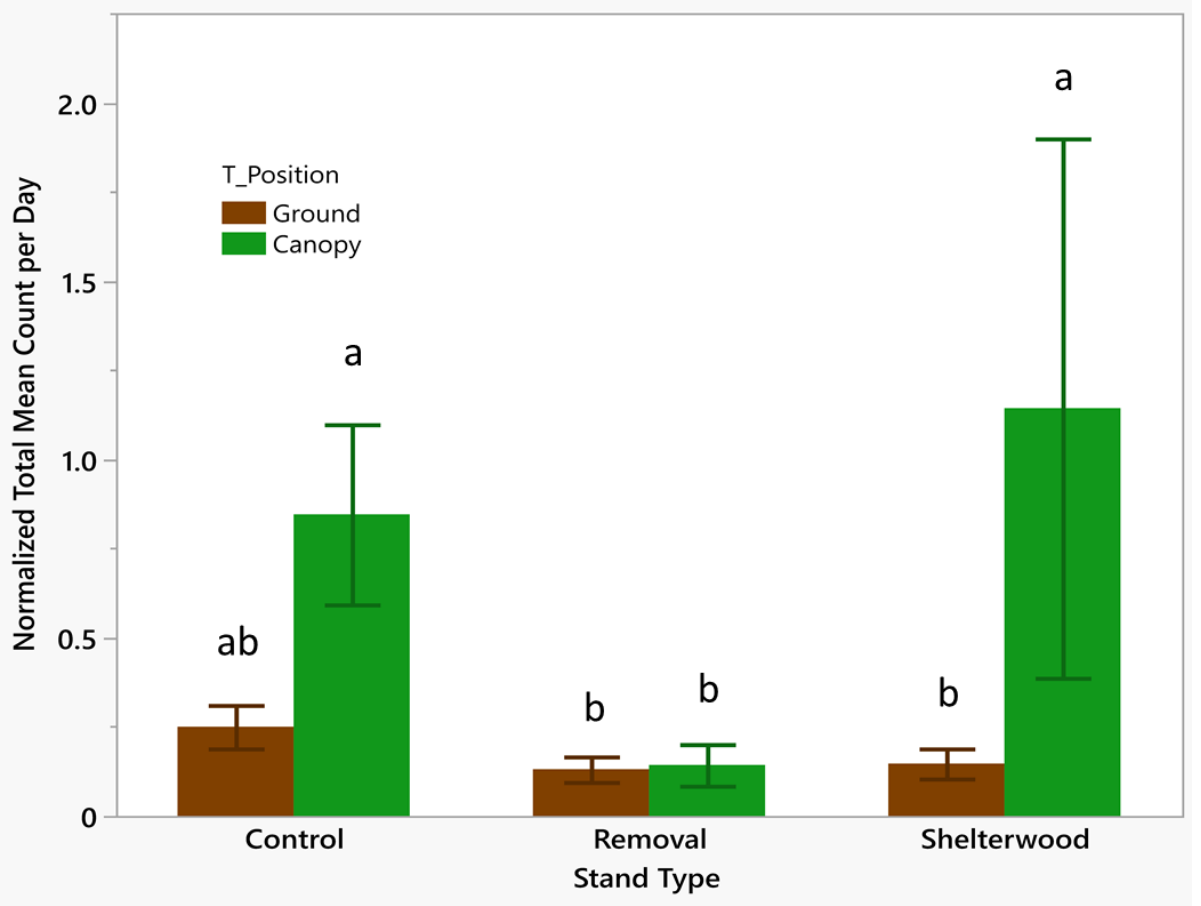

Fig 5. Significant interaction of insect abundance between the stand type and trap position.

Lepidopterans are more abundant in the canopies of black cherry in the shelterwood and control stands. The different letters above the bars indicate significance at $\alpha=0.05$. 


\section{Chapter 4. Conclusion}

The purpose of this study was to investigate potential pollinators of black cherry flowers and the effect of silvicultural practices on pollinator insects. Specifically, we attempted to identify VOCs found in the flowers of black cherry, confirm insect species are carrying pollen on their bodies, identify which insects are present during the flowering in the forest, and identify if stand management is affecting species abundance, richness, or diversity.

The results of this study (Chapter 2) demonstrate that black cherry flowers emit a blend of volatile organic compounds that can be found in other species of Prunus. The major floral compounds are known to attract various hymenopterans and lepidopterans, although low numbers of these species were captured in our traps. We found that species of dipterans, coleopterans, and hymenopterans collected off the flowery carry black cherry pollen on their bodies. This study also confirmed that Diptera was the most abundant insect found in the canopies of black cherry in the forest. We also found more dipterans visiting the canopy during the flowering period, suggesting that dipterans are being attracted to the canopy during the flowering of black cherry in the forest. In chapter 3 we investigated the impacts of stand management on the insect abundance, richness, and diversity during the peak flowering of black cherry. We found that dipterans were the most abundant insects captured in the shelterwood seed tree stands and lepidopterans can be found in the canopies where there is a diverse overstory. It was also found that there is a higher diversity and richness in the ground traps. This could indicate that there are more species with fewer individuals on the ground and more individuals of fewer species in the canopies. A higher diversity of vegetation in the understory and very little vegetative diversity in the canopy of black cherry could be the cause of this pattern. This 
indicates the major insect species in the canopies are there to use the specific resource of black cherry (i.e., pollen and nectar).

This study reported abundance insects captured in the canopies of black cherry during flowering. We have documented the volatile organic compounds emitted by the flowers. We have found that most of the insects captured in our traps were dipterans and are known flower visitors. Therefore, we believe dipterans are associated with the canopies of black cherry during flowering. We found a higher abundance of insect communities in the canopies of black cherry in the shelterwood stands when compared to the control stands. This indicates that insects are utilizing the canopies of black cherry in the treated areas and can still potentially pollinate the flowers. Because this study used passive traps, we do not fully understand which insects are successfully cross-pollinating flowers. We are only able to associate insects based on flowering period. We believe this indicates the insects we captured are being attracted to the canopy by the flowers.

The major insect species we discovered in the canopies should be investigated in the future to assess their pollination efficacy. The two distinct chemotypes emitted by the flowers should also be investigated to determine how many chemotypes are present in the ANF and whether these attract different insect communities. 